\title{
The Changing Shape of the World Automobile Industry: A Multilayer Network Analysis of International Trade in Components and Parts
}

\author{
Margherita Russo*1, Fabrizio Alboni ${ }^{2}$, Jorge Carreto Sanginés ${ }^{3}$, \\ Manlio De Domenico ${ }^{4}$, Giuseppe Mangioni ${ }^{5}$, Simone Righi*6, \\ Annamaria Simonazzi ${ }^{7}$
}

Working Paper No. 173

January $3^{\text {rd }}, 2022$

\begin{abstract}
In 2018, after 25 years of the North America Trade Agreement (NAFTA), the United States requested new rules which, among other requirements, increased the regional content in the production of automotive components and parts traded between the three partner countries, United States,

* CAPP Research Centre for the Analysis of Public Policies, University of Modena and Reggio Emilia, Italy

${ }^{1}$ Department of Economics, University of Modena and Reggio Emilia, Modena, Italy margherita.russo@unimore.it, corresponding author

2 Department of Economics, University of Modena and Reggio Emilia, Modena, Italy, fabrizio.alboni@unimore.it

${ }^{3}$ Facultad de Economía, Universidad Nacional Autónoma de México, Mexico, jcarreto@economia.unam.mx

${ }^{4}$ Complex Multilayer Networks Lab, Center for Information Technology, Fondazione Bruno Kessler (FBK), dedomenico@fbk.eu

${ }^{5}$ Dipartimento di Ingegneria Elettrica, Elettronica e Informatica (DIEEI), University of Catania, giuseppe.mangioni@unict.it

${ }^{6}$ Department of Economics, Ca' Foscari University of Venice Italy; simone.righi@unive.it

${ }^{7}$ Former Professor Dipartimento di Economia e Diritto, Sapienza Università di Roma, Italy, annamaria.simonazzi@uniroma1.it
\end{abstract}

The paper is part of the research project "Geopolitical and technological challenges for the automotive global value chains", PI Annamaria Simonazzi, funded by INET. The application on Mexico has been developed under the complementary project "Digital transformation in the automotive supply chain in Mexico", PI Jorge Carreto Sanginés, funded by UNAM PAPIIT IN309620. The authors wish to thank Emmanuel Lazega, Pietro Panzarasca and Riccardo Righi for their comments on the presentation of preliminary results of this paper at the ARS'19 Seventh International Workshop, and comments and suggestion emerging in the discussion with participants at the c.MET05 Policy Research Meeting on 31st March 2021, Italy, at the Gerpisa 2021 Colloquium, at the Conference on "L'industria dell'auto e gli investimenti della Cina nell'era dell'auto elettrica e della mobilità sostenibile", Modena University, 2021; and at the EUSN 2021 Conference. A special thanks to Martin Rosvall, who highlighted which output files could be used in the analysis of Infomap flow between clusters, and to Emanuele Murgolo for copy editing. 
Canada and Mexico. Signed by all three countries, the new trade agreement, USMCA, is to go into force in 2022. Nonetheless, after the 2020 Presidential election, the new treaty's future is under discussion, and its impact on the automotive industry is not entirely defined. Another significant shift in this industry - the accelerated rise of electric vehicles - also occurred in 2020: while the COVID-19 pandemic largely halted most plants in the automotive value chain all over the world, at the reopening, the tide is now running against internal combustion engine vehicles, at least in the announcements and in some large investments planned in Europe, Asia and the US.

The definition of the pre-pandemic situation is a very helpful starting point for the analysis of the possible repercussions of the technological and geo-political transition, which has been accelerated by the epidemic, on geographical clusters and sectorial specializations of the main regions and countries. This paper analyzes the trade networks emerging in the past 25 years in a new analytical framework. In the economic literature on international trade, the study of the automotive global value chains has been addressed by using network analysis, focusing on the centrality of geographical regions and countries while largely overlooking the contribution of countries' bilateral trading in components and parts as structuring forces of the subnetwork of countries and their specific position in the overall trade network.

The paper focuses on such subnetworks as meso-level structures emerging in trade network over the last 25 years. Using the Infomap multilayer clustering algorithm, we are able to identify clusters of countries and their specific trades in the automotive international trade network and to highlight the relative importance of each cluster, the interconnections between them, and the contribution of countries and of components and parts in the clusters. We draw the data from the UN Comtrade database of directed export and import flows of 30 automotive components and parts among 42 countries (accounting for $98 \%$ of world trade flows of those items).

The paper highlights the changes that occurred over 25 years in the geography of the trade relations, in particular with regard to denser and more hierarchical network generated by Germany's trade relations within EU countries and by the US preferential trade agreements with Canada and Mexico, and the upsurge of China. With a similar overall variety of traded components and parts within the main clusters (dominated respectively by Germany, US and Japan-China), the Infomap multilayer analysis singles out which components and parts determined the relative positions of countries in the various clusters and the changes over time in the relative positions of countries and their specializations in multilateral trades. Connections between clusters increase over time, while the rela-

tive importance of the main clusters and of some individual countries change significantly. The focus on US and Mexico and on Germany and Central Eastern European countries (Czech Republic, Hungary, Poland, Slovakia) will drive the comparative analysis.

\section{https://doi.org/10.36687/inetwp173}

JEL Codes: F14, L62, D85.

Keywords: international trade; regional specialization; automotive components and parts; dynamics of change; Infomap multilayer analysis. 


\section{Introduction. The automotive industry on the move}

The automotive industry is having an increasing impact on the world economy's growth (Helper \& Sako, 2010). The fragmentation of global value chains (De Backer \& Miroudot, 2012) and the emergence of regional specializations (Amighini \& Gorgoni, 2014a; Gorgoni et al., 2018) are crucial issues to address in order to understand the dynamics of change in the localization of production, in final demand for different types of vehicles and in demand for manufacturers' components. This is a bulk-gaining industry (Weber 1928; Rubenstein 1992; Klier and Rubenstein 2015; Brinks et al. 2018) that tends to locate next to consumers in highly regionalized value chains. Operating in an oligopolistic market, dominated by 14 firms globally controlling 62 brands (Hunkar, 2019) ${ }^{8}$, in the past 25 years, company strategies have been changing due to trade agreements and new suppliers, e.g., Mexico, which entered the North America Trade Agreement (NAFTA) in 1994, and China, which joined the World Trade Organization in $2001 .^{9}$

In addition, environmental constraints embedded in EU and China policies (DRC, 2019; European Commission, 2019) led to changes not only in products (cars and their components and parts) and their production technologies, but also in patterns of mobility, technologies and infrastructures. These structural changes make it necessary to extend analysis beyond the car sector to encompass the entire automotive and mobility sectors, drawing on several sources of information: OEMs' strategies and the changing locations of their suppliers in the global value chains; technological changes in products (cars, automotive components and parts) and in production technologies and materials; industrial and environmental policies; current individual and collective mobility infrastructures, and plans for their development; dynamics of consumers preferences and needs concerning individual mobility and the type of vehicles satisfying their needs, ranging from new to used vehicles, from individual vs shared vehicles, from compact cars to sport utility vehicles (SUV); changes in preferential trade agreements and their impact on trade networks of automotive components and parts.

All these interrelated features - at the core of the INET project on "Geopolitical and technological challenges for the automotive global value chains" are discussed in a series of interrelated papers, produced by the research team. In this paper we focus on the changing composition of international trade in automotive components and parts, analyzed on the basis of bilateral trade flows. In 1993, the relative weight of these trades accounted for almost $41.5 \%$ of the total exports of the automotive sector (the remaining share being motor vehicles). Twenty-five years later the weight had slightly increased to $42.5 \% .{ }^{10}$ A specific strand of economic literature explores international trade in the automotive global value chains, with an increasing number of papers using network analysis [Fagiolo, Reyes, \& Schiavo (2009),

\footnotetext{
Data on production of automotive vehicles by country and by car maker are available in Annex 1. China opened its economy to Western companies in mid-1980s and formally in 1992, when the Congress of the Chinese Communist Party approved the transformation towards a "socialist market economy".

10 In 2013 the share of components and parts was significantly higher, 49.1\%, highlighting that - after the 2008 crisis - the world trade of motor vehicles had not completely bounced back at its pre-crisis level.
} 
Hausmann et al., (2011), Barigozzi et al., (2011), Piccardi and Tajoli (2018), Piccardi and Tajoli (2014), Gorgoni et al., (2018)]. Trade data fits perfectly in a network perspective: datasets from official sources (such as United Nations) are easily available on a yearly basis for all countries over long time-spans, at a very detailed level of commodity specification. The literature on international trade adopts various methods and models to analyze trade networks' structure and dynamics. While it provides insights into the centrality of different geographic areas and the countries connecting those trade areas, less is known about two features of the utmost importance: the contribution of countries' bilateral trade to structuring trade clusters independent of the spatial location of countries, and the commodities that structure the relative position of countries. Analysis by clusters of countries allows us to study the effects of trade agreements on the geography of trade, while analysis of trade by components sheds light on the effects of the present transition to electric vehicles on trade in internal combustion engines and new components and parts, such as high-performing batteries and related components.

With our analysis we aim to identify the meso-level entities (intermediate between the individual countries and the entire network) that have characterized the international trade in automotive components and parts over the period 1993-2018. In particular, the paper addresses three major research issues. First of all, how can we identify the clusters of countries that define the trade network without reference to conventional geographical areas but rather to the recurring pattern of interactions in their bilateral trade flows in various components? Having identified these clusters, what is the contribution of countries and of automotive components in determining the relative importance and structure of the various clusters? Thirdly, what changes occur in the structure of those clusters over time, i.e., in the relative positions of countries and their specializations in multilateral trades?

To answer these questions, the paper is structured as follows. Section 2 surveys the literature on network analysis of trade data. Section 3 presents the data sources of bilateral exports and imports of automotive components and parts. Section 4 describes the methodology of multilayer cluster detection adopted in our analysis. Section 5 illustrates the results of the Infomap multilayer cluster analysis. Section 6 builds on these results to focus on trade patterns in the main clusters and on the impact on trade in components of the shift from internal combustion engines to electrical vehicles. Section 7 concludes with the focus on two clusters, US, Canada and Mexico, and Germany and the Central and Eastern European countries (Czech Republic, Hungary, Poland, Slovakia), and with a few hints on further developments in this research strand. ${ }^{11}$

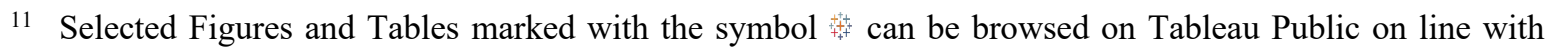
respect to data and community detection (part A), and to flows within and between clusters (part B). 


\section{Issues in the network analysis of automotive trade of components and parts}

To characterize the dynamics of international trade, the seminal paper by Fagiolo et al. (2009) studies the topological properties of world trade by focusing on distribution dynamics and evolution. More specifically, they employ a weighted network approach to characterize, for the period 1981-2000, the distribution of the most important network statistics: node connectivity, assortativity, clustering, and centrality, as well as link weights. The paper raises three points: the distributional properties of these statistics (and their correlation structure) in the sample period considered; their predictive implications; and the impact of adoption of alternative, economically meaningful, weighting schemes on the results. Focusing on the dynamics of change, the unit of analysis is the entire trade network. In a further contribution, Barigozzi, Fagiolo and Mangioni (Barigozzi et al., 2011) conceptualize international trade in a multiplex framework, where countries are embedded in trade in a series of 2-digit groups of commodities, each conceived as a separate international trade network. This perspective allows for comparison across the different cluster configurations in which countries are embedded, but overlooks the intertwining of lines of trade that characterizes patterns of mutual specialization and national power, as observed by Hirschman (Hirschman, 1977, 1980). This feature gives rise to multilayer clustering, which is essential for an understanding of international trading in components encompassed in global value chains.

In a recent contribution, Piccardi \& Tajoli (2018) focus on network structures to interpret the specific features characterizing international trade. They use a product complexity index from the Atlas of Economic Complexity (Hausmann et al., 2011) and focus on the features of subnetworks that offer indications to interpret the network's general characteristics. They conclude that the "trade networks that are more centralized are those that have more complex products."

Another approach is to study network components (subnetworks) and density in order to describe the changes in the overall structure of trade (Piccardi and Tajoli, 2018) and refer to the node brokerage measures in order to identify their roles in creating connections in the overall network, over time (Gorgoni et al., 2018).

In general, identification of subnetworks within a network - a classical methodological issue in the network literature (see Fortunato \& Hric, 2016, for a survey) - is specifically addressed when regionalization features are considered. However, the literature on international trade fails to address the complexity features of such networks. Their complexity derives from multiple types of interactions, measured by bilateral trade flows occurring over time among countries, with different overall volumes of trade and specific bilateral trades. Analysis of multilayer clustering yields evidence for creating a better understanding of features characterizing those subnetworks, but specific methods need to be adopted to identify the recurring patterns of countries' trades across the various items under analysis, rather than considering each group of items separately.

In their contributions on the international automotive trade, Amighini \& Gorgoni (2014) and 
Gorgoni, Amighini, \& Smith (2018) highlight the need to address the issue of regionalization and the countries' roles. They provide very accurate specifications of the data to be used in defining the unit of analysis, i.e., automotive trade in components and parts (which is a portion of the overall trade). They then aggregate automotive components and parts in groups to analyze trade regionalization in each group: countries' role in each of the networks and between networks is examined. Their analysis overlooks the fact that meso-level entities of complex networks cannot be disentangled by categorical partitions, such as grouping the countries according to their geographical position and grouping components and parts according to their relatively technological homogeneity.

To address analysis of the complex networks generated by trade, in this paper we focus on detection of multilayer meso-level entities - clusters of countries - and not on the centrality of individual countries in the aggregate network or subnetwork of groups of traded automotive components and parts. Although relevant for ranking countries, the centrality measures do not provide information about the multilayer meso-level entities determined by the relative positions of the countries in the various trade flows.

With our analysis we aim to identify the changes in the geography of international trade in the automotive global value chains in the period 1993-2017, comparing the configuration of international trade networks (exports and imports) in the years 1993, 2003, 2013 and 2017. In particular, our aim is to identify the groups of countries and components/parts around which the networks of relations are structured and how they change over time.

The direction and size of trade flows summarize information on countries' centrality in international trade, which depends on various dimensions, including skills and competences within the country (Hausmann et al., 2011), as well as the position of its companies in the automotive supply chain and the preferential trade agreements to which the country is party. The country's set of skills, wages, regulations, innovation ecosystems and absorptive capacity shape the structure of supply of automotive components and parts, which also depends on other production specializations in the country, as well as the location of domestic and foreign car makers' plants in the country, and on the role assigned by carmakers to supply from that country with respect to their global supply chains. Supply of components and parts, in fact, is embedded in the relationships between carmakers, with their different ramifications for assembly plants in the various final markets and their networks of supplier companies in the various countries. Regional trade agreements affect the centrality of countries by stimulating demand in specific trades and promoting changes in technologies and the organization of industries. These dimensions do not enter into the analysis of data at the country level but are to be considered in interpreting the results deriving from the analysis of trade flows. 


\section{Data}

\subsection{Automotive components and parts: selection criteria and data source}

Automotive components and parts cannot be identified using a standard classification, applied either to industry data or to statistics. As for the Standard International Trade Classification Revision 3 (SITC Rev. 3), no 2- or 3-digit aggregate would fit an analysis aiming to focus on the set of components and parts specifically traded in the automotive global value chains (see Annex 2 for details). Our list of items included in the analysis of international trade relies on the previous literature. In particular, we adopt the same list of 30 SITC Rev.3 items that Amighini \& Gorgoni (2014) identified as automotive components and parts. ${ }^{12}$ These items, listed in Table 1, were grouped into four main categories: Electrical and Electric Parts, Rubber and Metal Parts, Engines and Parts, Miscellaneous Parts.

Table 1 - List of automotive components and parts, by group, and their share of export, in the years 1993, 2003, 2013, 2017

\begin{tabular}{|c|c|c|c|c|c|}
\hline $\begin{array}{l}\text { group } \\
\text { description }\end{array}$ & SITC \& description & 1993 & 2003 & 2013 & 2017 \\
\hline \multirow{10}{*}{$\begin{array}{l}\text { Rubber and } \\
\text { Metal Parts }\end{array}$} & 6251_Tyres, pneumatic, new, of a kind used on motor cars (including station wagons and racing cars) & 6,47 & 5,31 & 6,95 & 5,86 \\
\hline & 62551_Tyres, pneumatic, new, other, having a herring-bone or similar tread & 0,56 & 0,43 & 0,66 & 0,44 \\
\hline & 62559_Tyres, pneumatic, new, other & 0,62 & 0,46 & 1,11 & 0,73 \\
\hline & 62591_Inner tubes & 0,30 & 0,12 & 0,13 & 0,10 \\
\hline & 62592_Retreaded tyres & 0,16 & 0,08 & 0,09 & 0,09 \\
\hline & 62593_Used pneumatic tyres & 0,19 & 0,08 & 0,08 & 0,05 \\
\hline & 62594_Solid or cushion tyres, interchangeable tyre treads and tyre flaps & 0,16 & 0,12 & 0,18 & 0,13 \\
\hline & 69915_Other mountings, fittings and similar articles suitable for motor vehicle & 0,77 & 1,12 & 1,00 & 1,11 \\
\hline & 69961_Anchors, grapnels and parts thereof, of iron or steel & 0,04 & 0,03 & 0,04 & 0,03 \\
\hline & Total & 9,28 & 7,76 & 10,23 & 8,55 \\
\hline \multirow{5}{*}{$\begin{array}{l}\text { Electrical and } \\
\text { Electric Parts }\end{array}$} & 76211_Receivers, radio-broadcast, not capable of operating without an external source of power...incorporating sound-recordin... & 3,69 & 3,15 & 1,69 & 1,20 \\
\hline & 76212_Receivers, radio-broadcast, not capable of operating without an external source of power...not incorporating sound-reco.. & 0,45 & 0,24 & 0,16 & 0,21 \\
\hline & 77812_Electric accumulators (storage batteries) & 3,04 & 3,89 & 4,81 & 5,76 \\
\hline & 77823_Sealed-beam lamp units & 0,19 & 0,13 & 0,10 & 0,06 \\
\hline & Total & 7,37 & 7,41 & 6,76 & 7,23 \\
\hline \multirow{7}{*}{$\begin{array}{l}\text { Engines and } \\
\text { Parts }\end{array}$} & 71321_Reciprocating internal combustion piston engines for propelling vehicles, of a cylinder capacity not exceeding $1,000 \mathrm{cc}$ & 0,78 & 0,42 & 0,37 & 0,38 \\
\hline & 71322_Reciprocating internal combustion piston engines for propelling vehicles, of a cylinder capacity exceeding $1,000 \mathrm{cc}$ & 8,86 & 8,56 & 6,13 & 5,72 \\
\hline & 71323_Compression-ignition internal combustion piston engines (diesel or semi-diesel) & 3,88 & 4,94 & 5,84 & 5,35 \\
\hline & 77831_Electrical ignition or starting equipment of a kind used for spark-ignition or compression-ignition internal combustion en.. & 2,84 & 2,41 & 2,76 & 2,72 \\
\hline & 77833_Parts of the equipment of heading 778.31 & 0,77 & 0,68 & 0,56 & 0,57 \\
\hline & 77834_Electrical lighting or signalling equipment (excluding articles of subgroup 778.2) & 1,70 & 1,77 & 2,78 & 3,50 \\
\hline & Total & 18,83 & 18,79 & 18,44 & 18,23 \\
\hline \multirow{12}{*}{$\begin{array}{l}\text { Miscellaneous } \\
\text { Parts }\end{array}$} & 7841_Chassis fitted with engines, for the motor vehicles of groups $722,781,782$ and 783 & 1,57 & 0,91 & 0,49 & 0,43 \\
\hline & 78421_Bodies (including cabs), for the motor vehicles of group 781 & 0,28 & 0,63 & 1,11 & 0,88 \\
\hline & 78425 B Bodies (including cabs), for the motor vehicles of groups 722,782 and 783 & 0,86 & 1,02 & 0,77 & 0,79 \\
\hline & 78431_Bumpers and parts thereof, of the motor vehicles of groups $722,781,782$ and 783 & 1,11 & 0,90 & 1,01 & 1,13 \\
\hline & 78432_Other parts and accessories of bodies (including cabs), of the motor vehicles of groups $722,781,782$ and 783 & 10,66 & 13,70 & 12,23 & 12,50 \\
\hline & 78433_Brakes and servo-brakes and parts thereof, of the motor vehicles of groups $722,781,782$ and 783 & 4,91 & 5,24 & 5,01 & 4,90 \\
\hline & 78434 Gearboxes of the motor vehicles of groups $722,781,782$ and 783 & 6,96 & 7,29 & 10,58 & 10,55 \\
\hline & 78435_Drive-axles with differential, whether or not provided with other transmission components & 1,73 & 1,62 & 3,82 & 3,58 \\
\hline & 78436_Non-driving axles and parts thereof, of the motor vehicles of groups $722,781,782$ and 783 & 1,07 & 1,17 & 0,00 & 0,00 \\
\hline & 78439 _Other parts and accessories, of the motor vehicles of groups $722,781,782$ and 783 & 34,87 & 33,06 & 29,10 & 30,83 \\
\hline & 82112 Seats of a kind used for motor vehicles & 0,51 & 0,49 & 0,44 & 0,41 \\
\hline & Total & 64,52 & 66,04 & 64,57 & 65,99 \\
\hline Grand Total & & 100,00 & 100,00 & 100,00 & 100,00 \\
\hline
\end{tabular}

Source: Authors' elaboration on UN Comtrade International Trade Statistics Database

12 Amighini \& Gorgoni (2014), Annex Table A1 Auto Parts Classification pp. 944-45. Such "classification is partly similar to the parts product listings adopted by the US Office of Aerospace and Automotive Industries (OAAI) ... [and] attempts to closely approximate the core automotive industry by excluding certain items for example, parts explicitly listed for motorcycles, golf carts, snowmobiles, agricultural equipment, etc." (ibid., footnote 5). 
The data source is the UN Comtrade International Trade Statistics Database. Under analysis is the set of bilateral export and import flows in 1993, 2003, 2013 and 2017. For those years, three-year average data are considered (the year under analysis, the year before and the following year). For each year and for each flow (import and export ${ }^{13}$ ) shares of trade flows of the various components and parts are computed. We focus on the trade relations of 42 reporting countries ${ }^{14}$ with all the countries in the UN Comtrade database. They represent, respectively, in 1993 and $2017,98.1 \%$ and $97.1 \%$ of the total exports of those 30 SITC items (details in Annex 3).

\subsection{Data description}

The four groups of components and parts show uneven distribution in terms of export shares (Table 1). The biggest and most heterogeneous group is Miscellaneous Parts, comprising a slightly increasing share of almost two thirds of trade. In 1993 the main items - respectively, almost 35\% and 11\% of total trade - were "other parts and accessories" (classified, respectively, in SITC 7843915 and 78432); the group Engines and Parts accounted for almost 19\% of trade, the main item being "Internal Combustion Engines"; Rubber and Metal Parts, with $9.3 \%$ of trade, which decreases in 2003. Electrical and electronic parts have a similar share over the four years, with the share of Electric Accumulators (storage batteries) increasing to almost $6 \%$ of total trade, while Sealed-beam Lamp Units fell to one third.

Figure 1 shows export (top panel) and import (bottom panel) shares by year and country. With regard to export, we observe a substantial change in the relative importance of the various countries. In 1993, the first five exporters of automotive components and parts - Japan, US, Germany, France and Canada - accounted for $67.3 \%$ of total exports, down to $44.8 \%$ in 2017 (only Germany managed to maintain its share). Conversely, China, Mexico, South Korea, and the Central European Economies (CEE, i.e., Czech Republic, Hungary, Poland, Slovakia) increased their overall share from $7 \%$ in 1993 to $33.5 \%$ by 2017 . The big shift occurred between 1993 and 2003; thereafter, China and Mexico consolidated their increasing importance, while the US continued its decline.

Turning to imports, Figure 1 highlights the marked imbalances in Japan's trade. Comparison

13 With regard to export flows, as in Gorgoni et al. (2018), "data are tabulated using importer records, more reliable than the corresponding exporter records".

14 The 42 countries are: Argentina, Australia, Austria, Belarus, Belgium, BeLux, Brazil, Canada, China, Czech Republic, Denmark, Finland, France, Germany, Hong Kong, Hungary, India, Indonesia, Ireland, Italy, Japan, Malaysia, Mexico, Netherlands, Philippines, Poland, Portugal, Romania, Russia, Singapore, Slovakia, Slovenia, South Africa, South Korea, Spain, Sweden, Switzerland, Thailand, Turkey, UAE, UK, Ukraine, US. The 1993 data (1992-1994) data refer to Belgium-Luxembourg, while for the following years there are only the data for Belgium. Thus, there are 42 countries in total (LUX never appears in the list). Details of the list of countries in Annex 3.

15 See Annex 2, Table A3 for the list of products included in the item 784.39 (SITC Rev.3) "other parts and accessories of the motor vehicles of groups 722, 781, 782", which are, respectively: 722: Tractors (excluding those of 71414 \& 74415); 781: Motor vehicles for the transport of person; 782: Motor vehicles for transport of goods, special purposes). 
with Germany suggests a different response by the companies of the two countries to the challenges of globalization. The US maintained considerable (though slightly declining) importance as an importing country, while Canada's poor performance (declining shares of both exports and imports) suggests a progressive marginalization of the country, possibly to the advantage of Mexico.

Figure 1 - Export and import by country, in 1993, 2013, 2003 and 2017

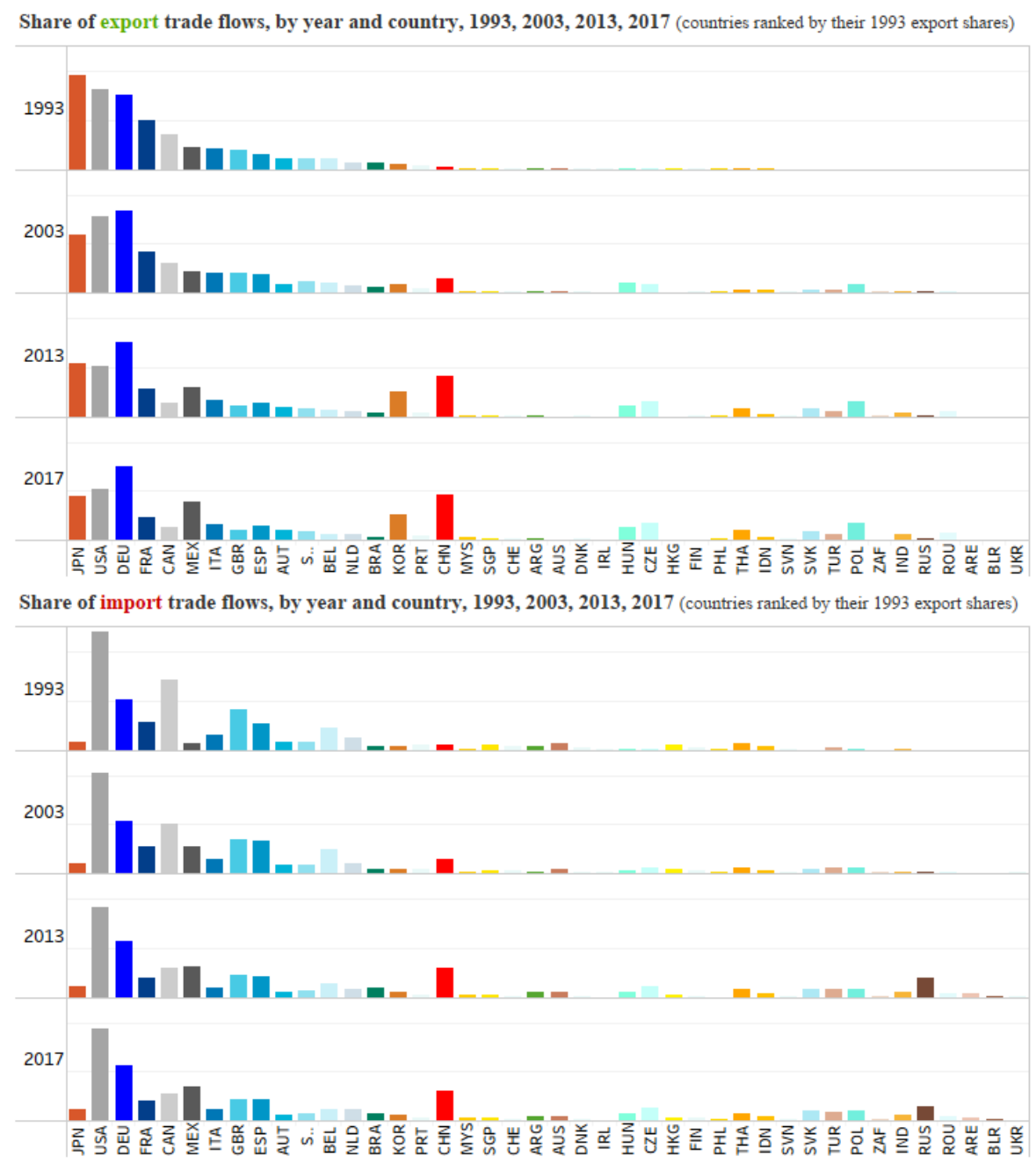

Source: Authors' elaboration on UN Comtrade International Trade Statistics Database

\subsection{Network of countries' bilateral trade flows}

The changes in the relative position of countries in their network configurations, for the years 1993, 2003, 2013 and 2017, are illustrated in Figure 2. The size of the nodes is proportional to the country's share of exports (top panel) and imports (bottom panel). The thickness of the link between countries is proportional to their trade flow, compared to the maximum share over the four years. It should be noted that for each year, export and import flows between two countries have the same thickness, but opposite direction. 
The graphs highlight a clear structure of subnetworks of trade flows with an evident geographical base: one subnetwork centered in Europe, on the left in each graph, another in the Pacific area (embracing countries in East Asia and the US and Canada), on the right in each graph. Changes in the relative importance of China, Mexico and Canada are accounted for by China's entry in WTO in 1994 and the implementation of NAFTA, which not only inverted the relative positions of Mexico and Canada in their trade with 


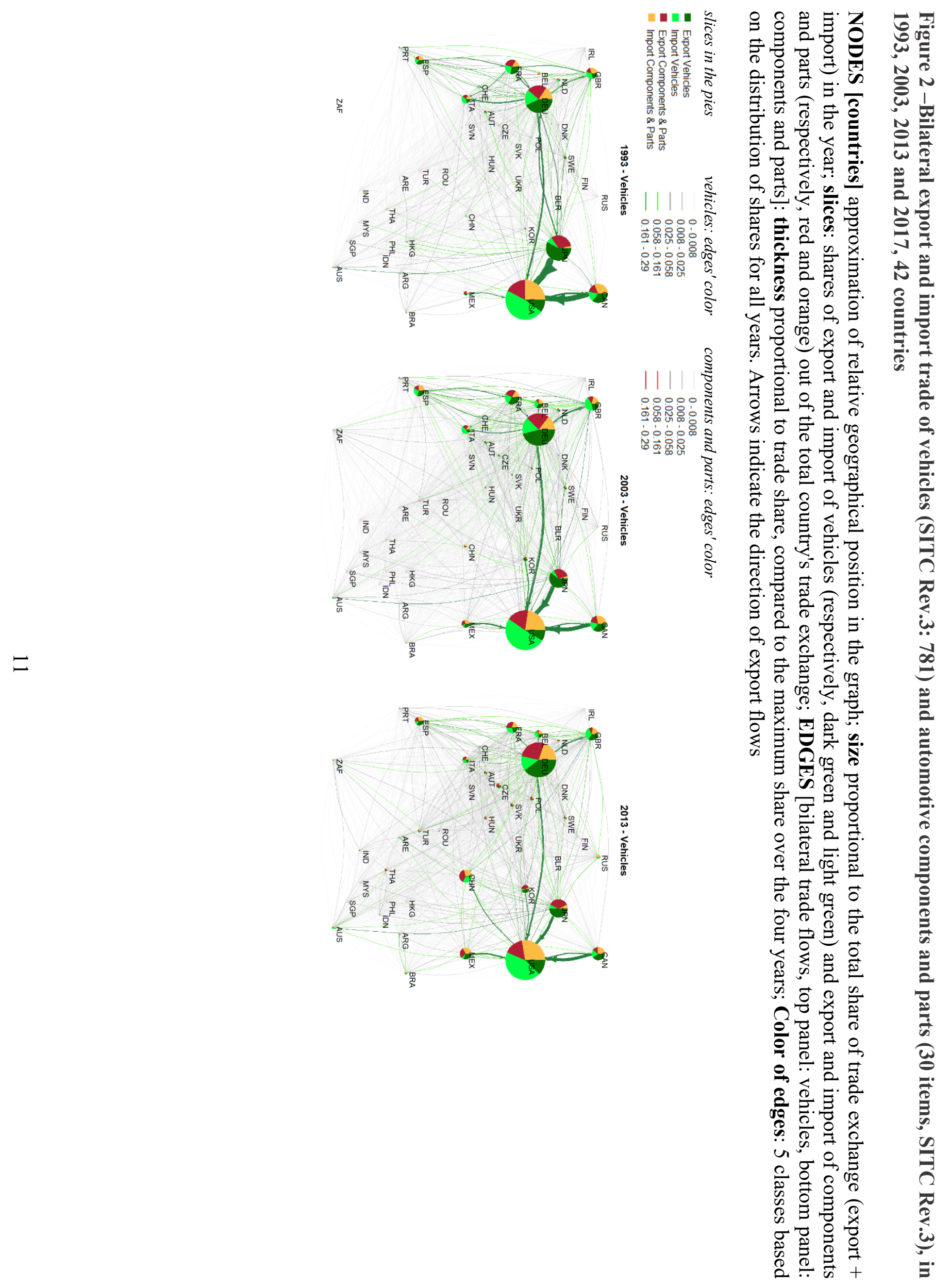




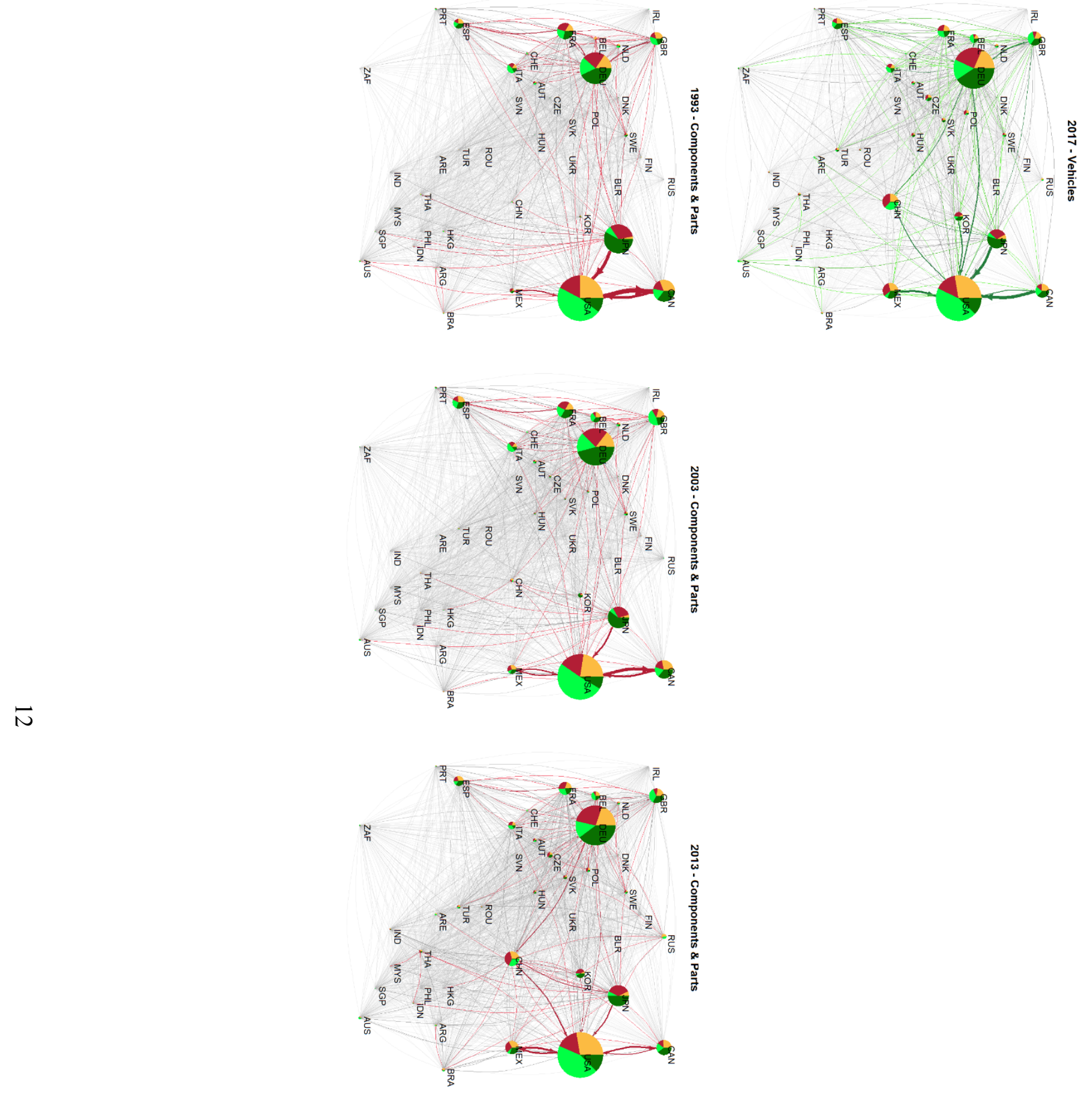




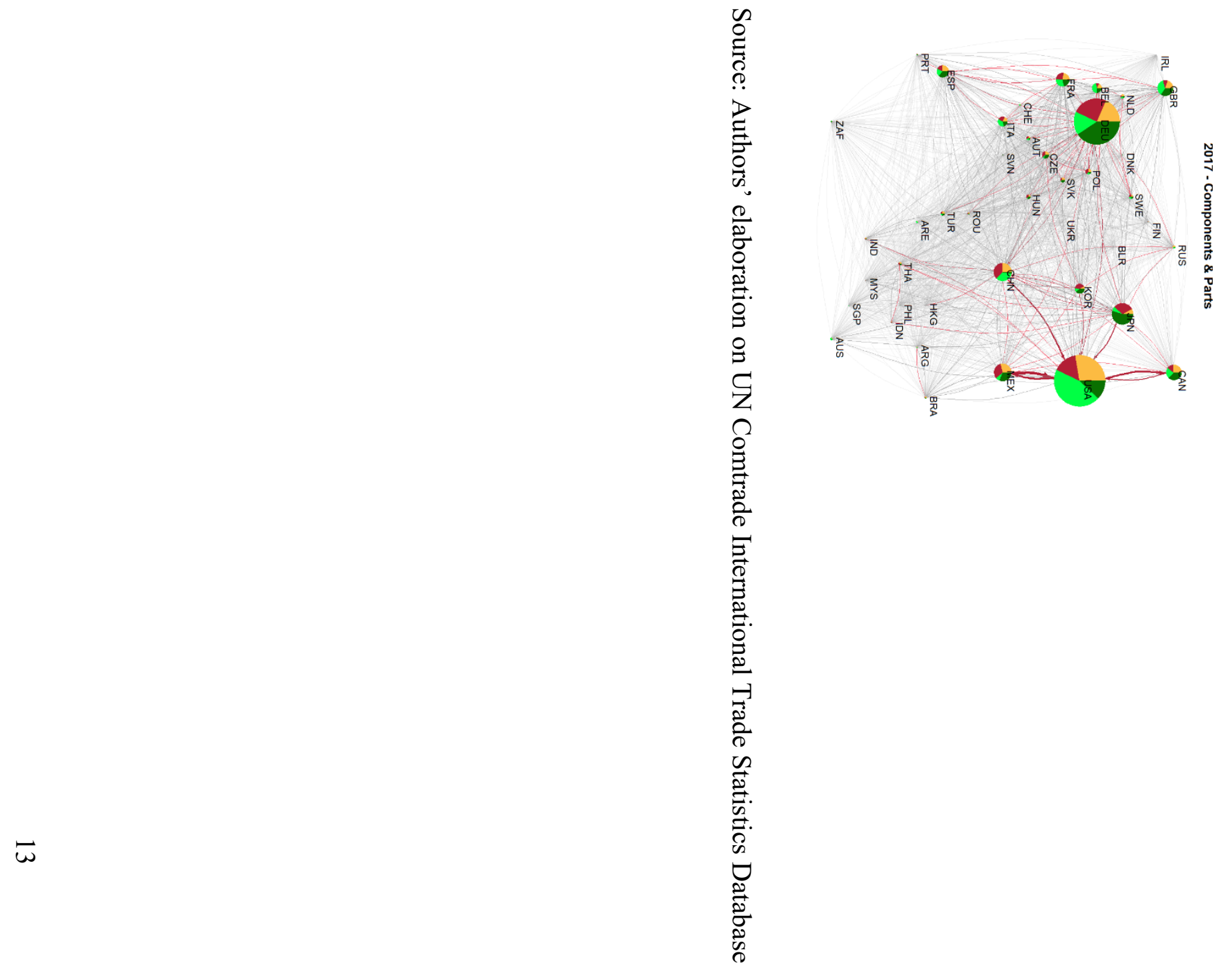


the US, but also stemmed the flows of Japan's exports to the US ${ }^{16}$, while the exports from China and Germany increased.

The change in the positions of Japan and Germany relative to the United States are explained by the changing strategies of the car manufacturers that over the two decades have moved their assembly plants to the United States and Mexico, becoming a source of demand for components and parts for their supply chains targeted the US car market. To identify the multilayer meso-level entities emerging in the trade flows, we refer readers to the Infomap multilayer methodology which we will describe in detail in Section 4.

\section{Methods: multilayer network analysis}

\subsection{A multilayer method for module detection}

Classical network models do not take account of the complexity exhibited by systems in which multiple levels of descriptions are required to preserve microscopic information on interactions of different types that evolve over time. To this end, it is expedient to use more sophisticated models such as multilayer networks, which are able to take into account the additional levels of complexity (Boccaletti et al., 2014; De Domenico et al., 2013; Kivela et al., 2014). In this class of models, a pair of nodes can be related by one or more types of interactions or relationships. Each interaction type is mapped into a 'layer' of description, collecting all the pairwise interactions of the same type: within each layer, nodes are usually referred to as state-nodes and their connections define intra-layer connectivity. The set of all state-nodes corresponding to the same node defines their physical node. Connections between state-nodes of the same physical nodes, or between state-nodes of distinct physical nodes, define inter-layer connectivity, which plays an important role in shaping the collective phenomena emerging from the dynamics on the top of the system (De Domenico et al., 2016).

We use the Infomap multilayer algorithm of module detection (Rosvall and Bergstrom 2008; De Domenico et al. 2015) to identify meso-structures (hereafter clusters) that are intermediate between the network as a whole and the individual countries (nodes) that have trade relationships with other countries.

\subsection{Infomap multilayer algorithm}

The modules detection method, introduced by Rosvall and Bergstrom $(2008,2011)$, is based on information theory: to detect modules in complex networks, the method minimizes the length of a two-level description of a simulated flow circulating through the network. The first level of description concerns the nodes between which the flow moves, the second the sub-areas of the network, i.e. modules, in which the flow tends to circulate for a long period

16 The trade war with the US hampered the FDI of Japanese OEM and their tier 1 in the US (Carreto Sanginés et al., 2021). 
before exiting. Therefore, each detected module maximizes the probability of a considered random walker remaining within its boundaries before moving into another module. This method is implemented in an algorithm called 'Infomap' ${ }^{17}$ extended by De Domenico et al. (2015) to run over a multilayer-or multiplex-structure.

The Infomap multilayer algorithm: (a) considers in each layer only one specific type of relationships to determine intra-layer connections; (b) connects all the projections (i.e. statenodes) of the same node (physical-nodes) with inter-layer connections. Overcoming the limits of the first-order Markov model that "suffers of memory loss and washes out significant dynamic patterns" (Edler et al., 2017, p. 1), the Infomap multilayer algorithm implements recursive computation of a random walker.

\subsection{The multilayer model of international trades over time}

Data presented in Section 3 are mapped in the multilayer model. To obtain the most effective estimations, the trade data will be considered at the most disaggregated level available in trade statistics. We consider 60 layers (30 components and parts, by import and export) for each of the four years, and each with approximately 42 nodes (the countries). ${ }^{18}$

The algorithm is designed to identify multilayer meso-scale entities (clusters of countries and their specific trades) for each year. It provides metrics to assess the relative importance of the clusters detected and the contribution of the individual countries and their links (weighted bilateral trades) in determining those clusters. The algorithm normalizes trade flows occurring within layers and between layers in an index ranging from 0 to 1.

The Infomap multilayer algorithm does not simply measure the inflow and outflow of countries' trades, and does not reflect the weight of aggregated bilateral flows between countries. ${ }^{19}$ Instead, the Infomap multilayer algorithm identifies clusters of countries in the world trade of automotive components and parts and permits decomposing the flow in terms of the underlying layers (components and parts) and nodes (countries) within and between the detected clusters of countries, thus identifying the building blocks to answer the research questions we address in this paper.

\section{Results: clusters of automotive trade and their determinant over time}

In this Section, the results will be presented by focusing, first of all, on the clusters of automotive trade detected by the Infomap algorithm and assessment of the connections between

17 Infomap solves the main problems with Newman and Girvan (Newman \& Girvan, 2004) in identifying modules of very different sizes and, in addition, it allows for detection of overlapping modules (Fortunato \& Hric, 2016), so that each agent/node can belong to more than one of them.

18 The weights adopted in the analysis, the structure of the net file, and optimal relax rate for the multilayer algorithm are presented in Annex 4.

19 At a country level, a measure summarizing those flows can be obtained by computing a centrality measure that takes into account recursive interactions among nodes. 
clusters of countries in terms of the countries' specific trades across clusters. Building on the Infomap flow metric, in Section 6 we read the results in terms of trade shares of exports and imports. $^{20}$

\subsection{Meso-scale entities, by year}

In contrast with geographical clusters, where each country has a unique position in the trade network, the clusters identified using the Infomap multilayer algorithm must be interpreted keeping in mind two general aspects deriving from the algorithm itself. First of all, clusters do not necessarily contain countries exclusively, but in terms of their relevance due to the connections they have among them in terms of the bilateral weighted trades of export and import of the 30 SITC codes. This implies that - for some specific trades - a country might belong to more than one cluster. Secondly, when we compare clusters over time, we consider the countries and specific trades characterizing them, and we assign a label and color to make the comparison easier, but we should not forget that the internal composition of each cluster in terms of countries and trades might change over time. Indeed, it is precisely this focus on the structural determinants that can be achieved with a multilayer clustering: a reason why the Infomap algorithm provides a new perspective on the analysis of trade networks and on countries' positions in the changing clusters over time.

A summary of the number of clusters and changes occurring over time is presented in Figure 3 with alluvial diagrams ${ }^{21}$, in Figure 3 with respect to the relative importance of each cluster and in Figure 4 with a view to the connections among clusters.

In Table 1 above we noted that, in the period 1993 - 2017, the overall composition of exports by SITC component and part shows little change. On processing the countries' bilateral trade flows with the Infomap algorithm, we observe a truly considerable change in the structure of the international trade network: the number of multilayer clusters decreases over the four years (from 39 in 1993 to 16 as from 2003), the main three clusters have an increasing weight, and - as from 2003 - the third top cluster has only a few countries (right panel in Figure 3). Figure 3 highlights the emergence of specific clusters in 1993, which subsequently merge into major clusters, as in the case of cluster 6, which in 2003 was incorporated into the cluster led by Germany, and of clusters 5, 7 and 8, which were incorporated into the cluster led by Japan $^{22}$.

We could have detected such subnetworks in a geographical network analysis, but no other

20 Infomap flow is decomposable by node (the countries), by layer (the SITC codes for the export and import trades) and by flow from state-node to state-node (which represent the random walk paths along the countries bilateral trades of a specific component), thus providing information on each of the determinants of the detected clusters. See Annex 6 with the details on the Infomap output files analyzed in this section.

21 An alluvial diagram represents changes in network structure over time.

22 In 1993, these clusters were led, respectively by: JPN with Reciprocating internal combustion piston engines for propelling vehicles; CZE with Drive-axles with differential, whether or not provided with other transmissions; KOR with Inner tubes; CHN Anchors, grapnels and parts thereof, of iron or steel. 
analysis would have revealed the relative importance of bilateral export and import trades of components and parts in determining that result. Before describing the characteristics of the clusters detected by the Infomap algorithm, it should be noted that the multilayer algorithm clearly yields a spatial distribution of clusters that is largely associated with the geographical position of countries, but the algorithm also singles out specific sub clusters in those areas, such as the ones led by the Czech Republic, Thailand, Indonesia, and Turkey, and their characterizing trades.

Figure 3 - Clusters of countries: alluvial, 1993 - 2017

In each graph, labels on the left side (1993) and on the right side (2017) refer to the top combinations of country/layer (at most four are shown). Colors refer to the ID of the cluster and are associated with the top country-and-layer. Colors of clusters with a very low Infomap flow may not be visible. Communities are ranked by their value of Infomap flow

\section{(a) Size of cluster proportional to the Info- (b) Size of cluster proportional to map flow

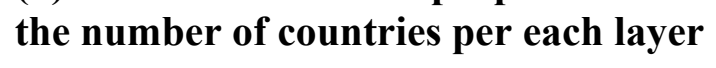

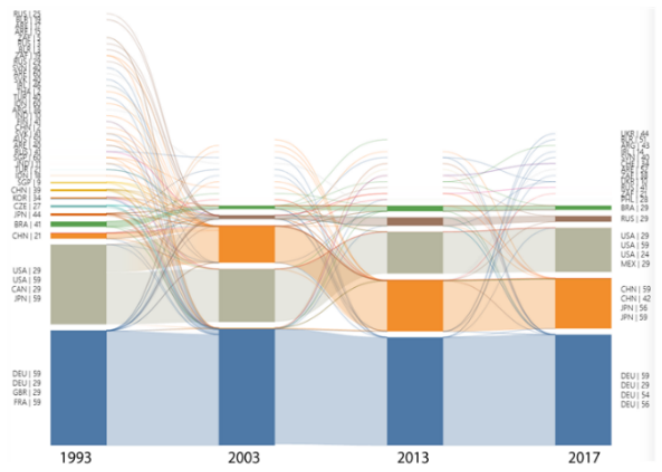

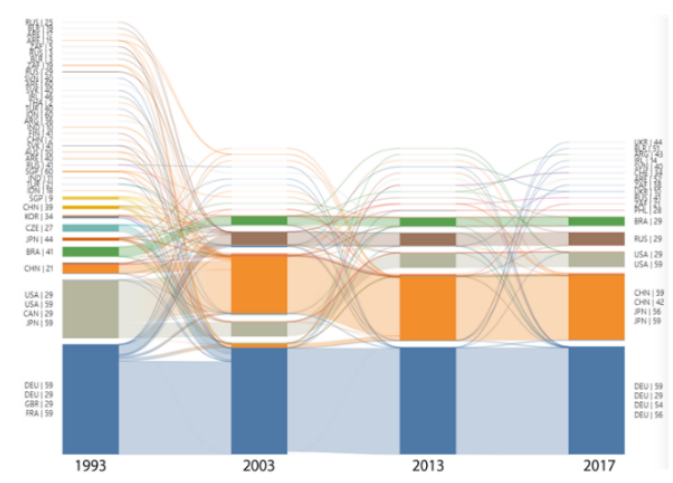

Source: Authors' elaboration on UN Comtrade International Trade Statistics Database

Figure 4 - Infomap flow by cluster

Only the first ten clusters are displayed

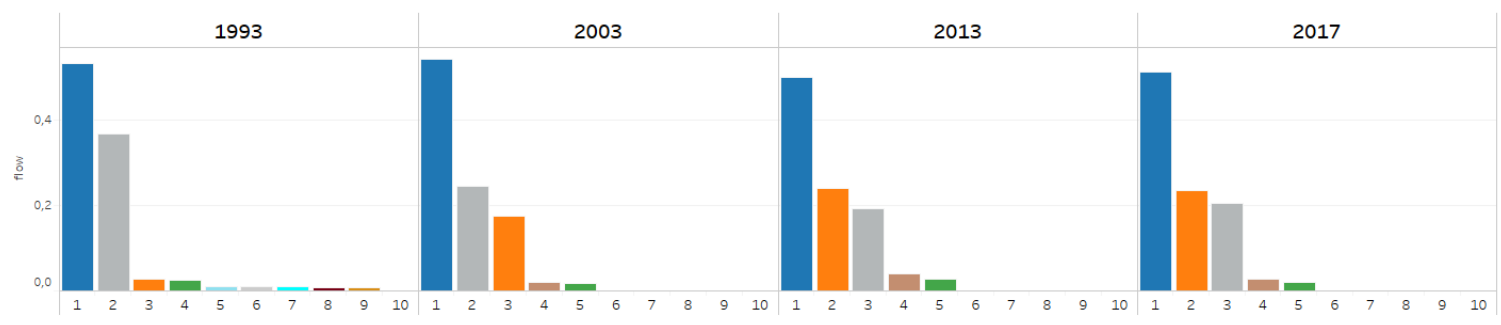

Source: Authors' elaboration on UN Comtrade International Trade Statistics Database

For each year, we analyze the list of countries and specific trades belonging to each cluster. In what follows, we provide, first of all, a summary of the results in terms of clusters, and then go on to comment on the interconnections between clusters.

In 1993, there were:

- $\quad$ two main clusters (blue and grey), dominated by Germany, cluster 1, and 
Japan and the US, cluster 2;

- $\quad$ two smaller clusters (orange and green), encompassing, respectively, East

Asian economies (China, Singapore, Thailand), cluster 3, and Brazil and Argentina, cluster 4;

- $\quad$ three very small clusters and an array of other clusters of negligible importance, but signaling very specific trade flows, which will be discussed below.

Since 2003:

- $\quad$ East Asia and the US, with Canada and Mexico, have split apart, and three main clusters have emerged, with practically the same overall importance, dominated respectively by Germany (blue), the US (grey), and Japan, and later also with China (orange).

- Two more clusters: the one already noted in 1993, centered on Brazil and Argentina (green), and a new one, led by the Russian Federation (brown), growing in importance from 2003 to 2013 and sharply declining in 2017.

The four graphs in Figure 5 summarize the relative importance of trades of automotive components and parts within and between clusters ${ }^{23}$. The clusters are drawn as circles with the same colors they have in the alluvial (for the 9 main clusters, green for all the others) and area proportional to the Infomap flow generated within the cluster. The thickness of links between clusters is proportional to the flow between clusters. The graphs highlight the relative sizes of the clusters and the existence of interconnections that are summarized in Table 2. Interconnections between clusters increase from $18.5 \%$ of the overall Infomap flow, in 1993 , to about $30 \%$, in $2017^{24}$.

\section{Figure 5 - Infomap flows within and between clusters countries}

Clusters are drawn as circles with area proportional to the Infomap flow generated within the cluster; the cluster border's intensity of color is proportional to exiting flow; thickness of links between clusters is proportional to the Infomap flow between clusters

1993

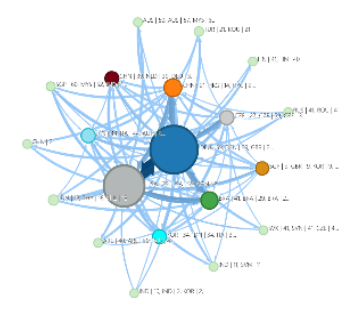

2003

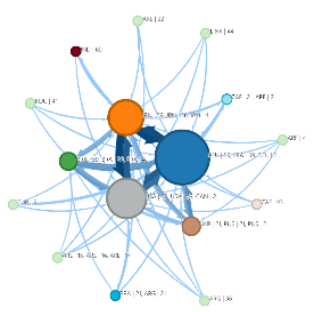

2013

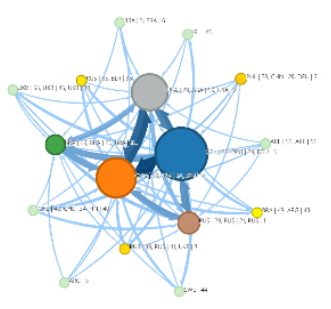

2017

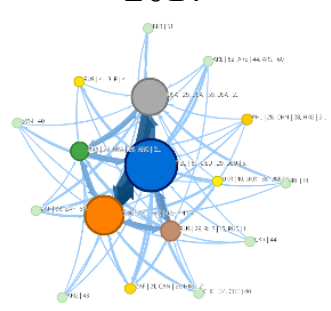

23 Clusters and their relations are represented in the graphs realized with the visualization tool of Infomap Network Navigator and with Adobe Illustrator to change colors of nodes. Adapted from Errore. Riferimento a collegamento ipertestuale non valido. [accessed 12/01/2021]

24 In order to explore Infomap flow generated within and between cluster, it is necessary to consider all statesnodes, regardless of the module they belong to and then aggregate data by module. See Annex 6 for details on the Infomap output file used to implement such analysis. 
Source: Authors' elaboration on UN Comtrade International Trade Statistics Database

Table 2 -- Percentage of Infomap flow generated within and between clusters, by year

$\begin{array}{lll}\text { year } & \begin{array}{l}\text { within the } \\ \text { cluster }\end{array} & \begin{array}{l}\text { between clus- } \\ \text { ters }\end{array} \\ 1993 & 81.5 \% & 18.5 \% \\ 2003 & 75.5 \% & 24.5 \% \\ 2013 & 70.5 \% & 29.5 \% \\ 2017 & 70.1 \% & 29.9 \%\end{array}$

Source: Authors' elaboration on UN Comtrade International Trade Statistics Database

We compare the characteristics of the clusters in the four years, in an overall time span of 25 years, by focusing on four main statistics: the number of state-nodes (i.e., the projections of each country in the trade networks of import and export for each SITC code, that are the layers in the multilayer model), the number of links and of countries; the connections generated by trades within the cluster (measured by the Infomap "flow within") and the connections of each cluster to all the other clusters (measured by the "exit flow"). These statistics are presented in Figure 6 with regard to the first nine clusters (s represent the various clusters). The legend - with colors and names of the clusters by year - makes clear which is the leading country, i.e. the one having the highest Infomap flow in a layer (with the smallest clusters, starting from the $6^{\text {th }}$, having a different leading country characterized by a specific trade in each of the four years).

Figure 6 - Clusters statistics: number of state-nodes, links and countries; flow within and exit flow

Only the first nine clusters are included in the graphs
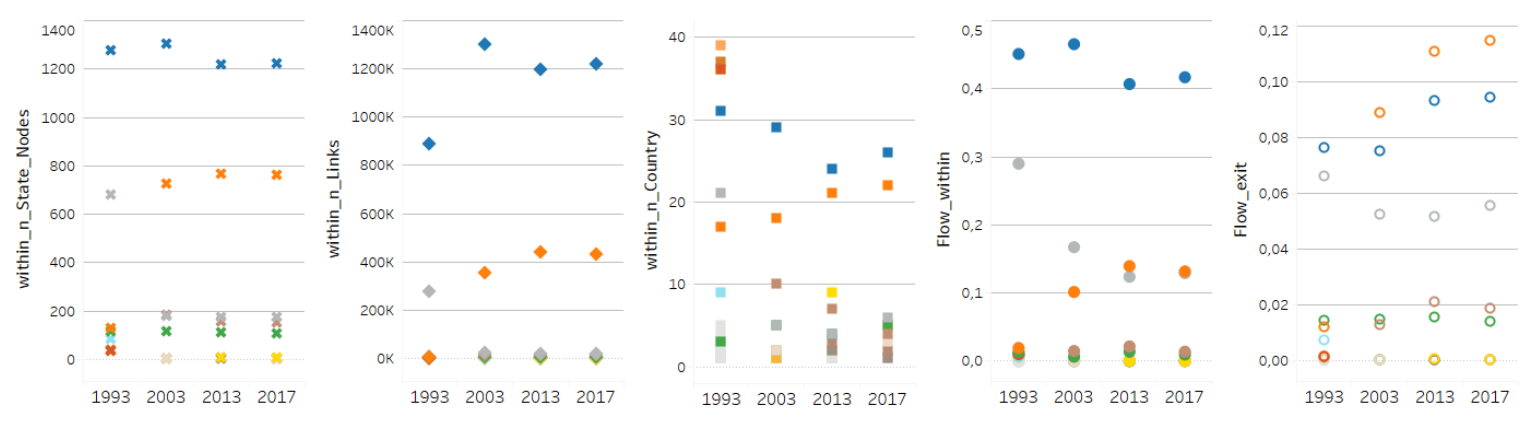

Legenda: clusters by year are identified by the name: "country | SITC code"

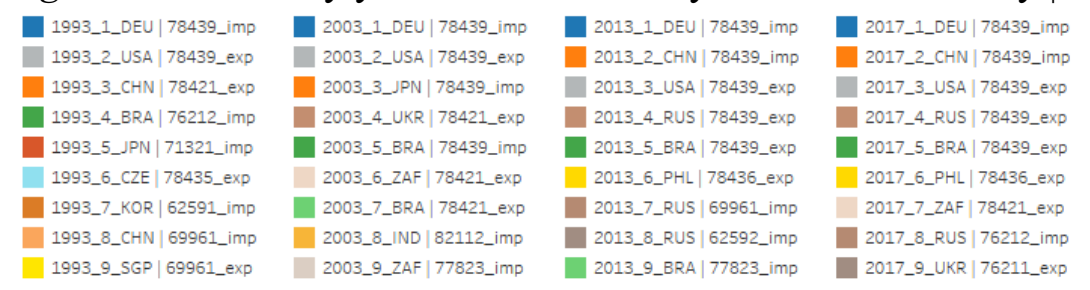

Source: Authors' elaboration on UN Comtrade International Trade Statistics Database

The large (only slightly declining) number of links and state nodes in the Germany-led 
cluster denotes the variety of export and import trades characterising this cluster. Both links and state node increase in the China-and-Japan-led cluster, while the US-led cluster has a lower number of state nodes, there being fewer countries in the cluster.

Focusing on the number of countries per cluster, in 1993 the three very small clusters 5, 7 and 8 involved trades with 35-40 countries. Since 2003, small clusters have involved a lower number of countries, which can be put down to the more focused specialization in trade of smaller clusters and the growing importance of the largest clusters - led by Germany and by China (respectively, cluster 1 and cluster 2) - in terms of numbers of embedded countries.

The Infomap flow within clusters illustrates four main dynamics that highlight the main differences among clusters and their changes over time:

- the Germany-led cluster (blue) has a very high level of flow - generated by trades within the cluster, it declines in 2003 and rises again in 2017;

- the grey cluster was initially the second largest group and, as it declines in importance, becomes, in 2013, the third cluster; in 1993 it was led by the US and Japan, since 2003, it is led by the US and mainly embeds the NAFTA countries;

- the orange cluster, led by Japan and later on by China, shows an increasing flow within, and becomes, in 2003, the second largest cluster;

- all the other clusters have little relevance and a relatively stable dynamic.

The clusters' exit flows highlight the connections across clusters, increasing for most clusters, with the exception of the cluster led by the US, which slightly decreased in 2013 with respect to 2003, to increase again in 2017. In 2017 the exit flows in the clusters led by Russia and Brazil decreased with respect to 2013. Since 2003, the cluster led by China has shown a greater exit flow. Comparing 1993 and 2003, Germany showed an increased flow within and a decreased exit flow, while the opposite holds true in 2017 with respect to 2013.

Data on Infomap exit flows highlight the contribution of countries in connections across clusters with bridges across specific trades in components and parts that keep the whole network together. Significantly, those bridges can propagate shocks in multiple clusters and across clusters (depending on the nature of the shocks, such as a new trade agreement or a change in final demand due to new requirements for vehicles). Exploration of cluster connections may reveal the relative importance of countries in terms of specific advantages they could derive from the relations over more clusters and their strategic position with regard to the supply of automotive components and parts that might result in a constraint (essential) for the countries in the various clusters. The following section studies what components and parts are interlinking those trades and connections and toward/from which clusters and countries. 


\subsection{Infomap flow by country and layer of export and import SITC codes}

\section{Infomap by country}

On comparing, in Figure 7, countries' trade shares (of export and import) and Infomap flows ${ }^{25}$, we observe that the latter summarizes information on trade shares that cannot simply be detected with the aggregate values of trade by country. Japan is a case in point: it has significant exports to many countries, but does not import from many countries and has a limited value of imports (see also Figure 2).

With regard to the Infomap flow, although declining, the US keeps its relative importance in the world trade in automotive components and parts, while its main partners showed substantially opposite trends from 1993 to 2017: Canada moved from the $5^{\text {th }}$ to the 9th position, while Mexico advanced its position from $11^{\text {th }}$ to $4^{\text {th }}$. Germany's Infomap flow initially showed decline, and subsequently continued growing, gaining the $1^{\text {st }}$ position. The United Kingdom, France, Spain and Italy show similar dynamics with a slight recovery of their relative importance in the last year observed. As for Japan, the Infomap flow did not change significantly, while Russia showed a significant increase in the Infomap flow in 2003, after which it decreased. An array of other countries (in Europe, Asia, Middle East) showed increasing importance, offsetting the decreasing significance of countries with historical presence in the automotive international trade.

\section{Figure 7 - Trade flows and Infomap flow by year}

Left panel: shares of export trade values; central panel share of import, right panel: Infomap flow by country (and export and import contribution, respectively lower and upper segment in the histogram). Countries ranked by 1993 trade export shares

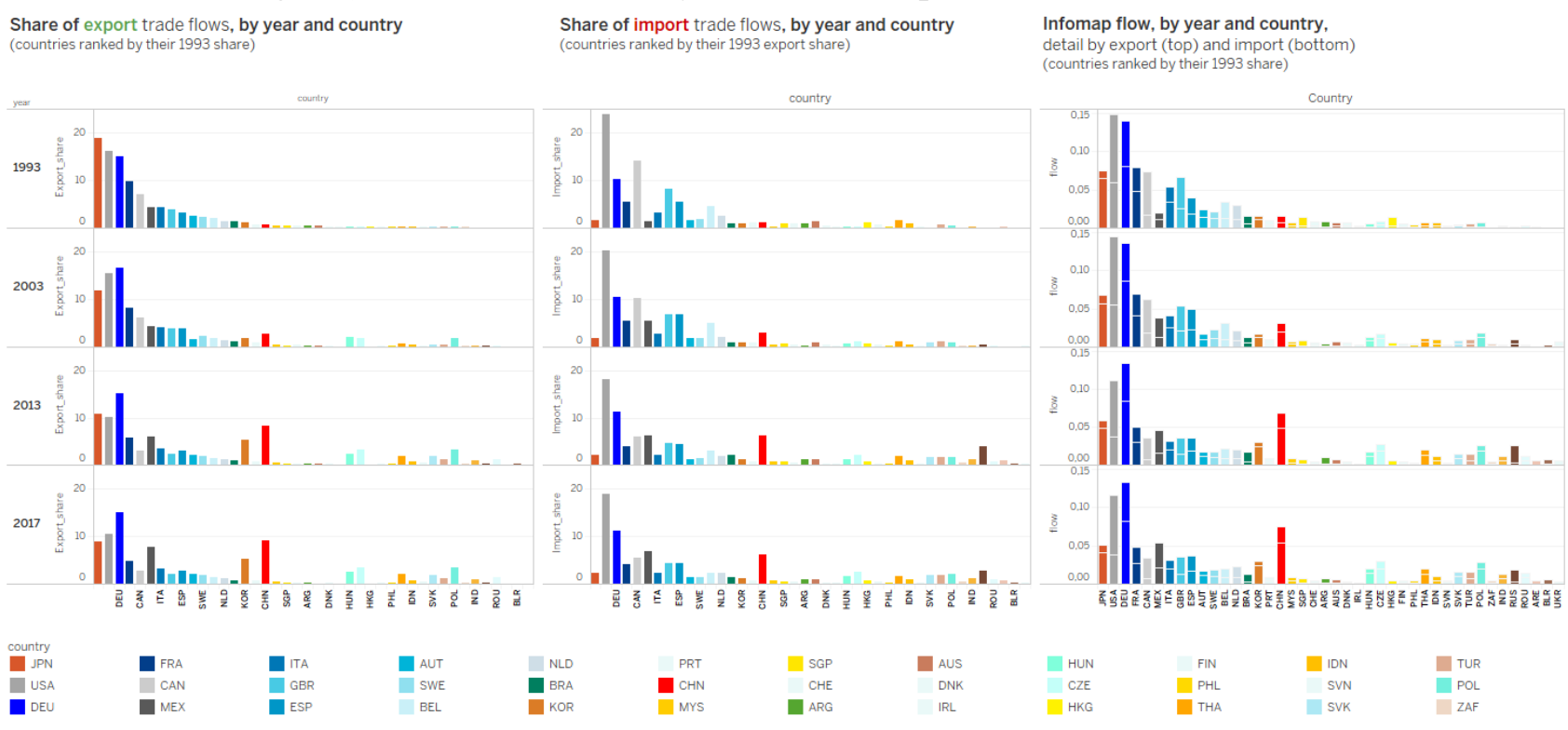

25 Infomap flow and trade shares by country can be browsed on line 
Source: Authors' elaboration on UN Comtrade International Trade Statistics Database

To assess the countries' contribution in determining the dynamic of change in the meso-entities, Figure 8 presents the results of the cluster analysis of the Infomap flow and of the trade shares of export and imports by country, respectively in panel (a) and (b) ${ }^{26}$. As for Infomap flow:

- $\quad$ Germany maintained a very high contribution, only slightly declining;

- $\quad$ the US saw a lower Infomap flow, and only in 2017 did it grow;

- China and Mexico, having a similar Infomap flow in 1993, were on the rise, but Mexico fell to a lower level in 2017;

- $\quad$ starting from a similar level, France and Japan, and Canada and the United Kingdom fell to lower levels, but the UK was less important in 2017; Spain and Italy had lower positions in 2017 and declined over the four years, arriving at the same level as Canada and the United Kingdom;

- $\quad$ South Korea, the Czech Republic and Poland rose to higher positions;

- $\quad$ for a group of eight countries, Infomap flow increased slightly (cl-5), namely

Brazil, Hungary, India, Romania, Russian Federation, Slovakia, Thailand and Turkey;

- $\quad$ two other groups of countries, with very low levels of Infomap flow, differed in their declining trends (cl-6, with 10 countries, and cl-7, with seven countries).

With regard to the dynamics of export and import share, similarities between countries give rise to seven single country clusters (United States, Germany, Japan, China, Mexico, Canada, France), smaller groups with two-three countries and one larger group with very small trade shares.

Figure 8 - Dynamics of changes in the contribution of countries in determining the meso-scale entities over the years

\section{(a) Clusters of countries' Infomap flow in the (b) Clusters of countries' trade shares four years in the four years}
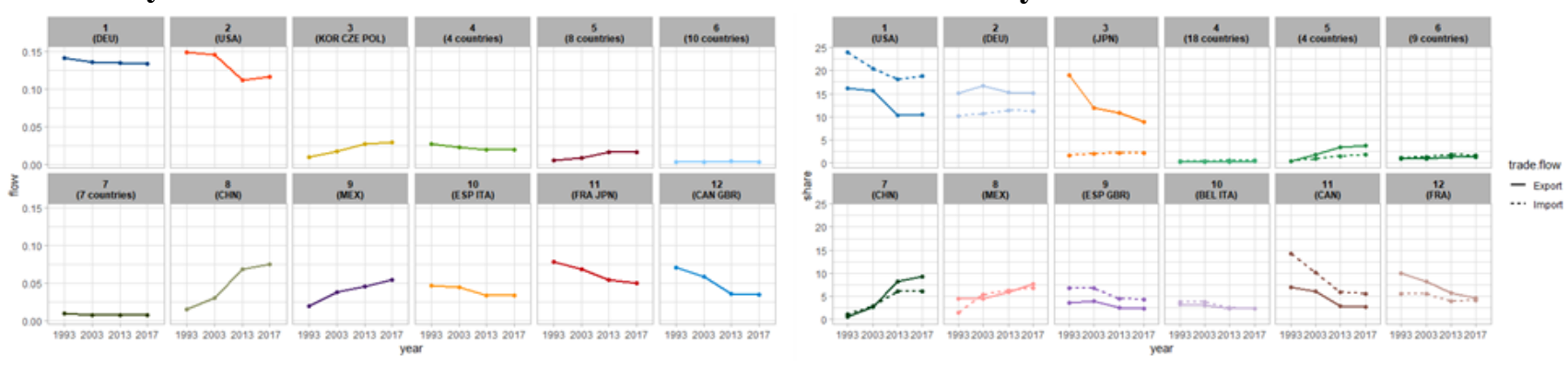

26 Details of the cluster analyses (hierarchical clustering, Ward methods and Euclidean distance), dendrograms and countries belonging to the two sets of clusters are available upon request. 
Source: Authors' elaboration on UN Comtrade International Trade Statistics Database

These results by country are not new, and they can also be found by computing a centrality measure such as the Page Rank, which is in fact closely correlated with the Infomap flow (see Annex 5). However, a centrality index provides no information on the meso-scales entities, which is why we adopted the Infomap multilayer algorithm, which allows to single out which countries and SITC codes are specifically determining the cluster in each year.

Infomap by country and layer

In what follows we explore the distinctive characteristics of each cluster of countries identified by the algorithm, in terms of: overall importance of the cluster, countries belonging to cluster, components that are traded, and type of trade flow (export vs. import).

Figure 9 shows that, while in 1993 clusters were characterized by an array of countries and components, since 2003, only the biggest three clusters have been characterized by a variety of countries and a mix of all automotive components and parts, while the smaller clusters comprise only a few countries mainly or solely exporting or importing a few components and parts.

Focusing on the Infomap flow by country (Panel b), we observe that while in 1993 there was a significant presence of the main countries in more than one cluster, this feature was no longer significant in the following years, when more distinct clusters appeared. On looking at the Infomap flow generated by export and by import, by cluster and by country (Panel d), we are able to single out the different emergent characteristic of clusters over the years.

In 1993, the two top clusters, US \& Japan-led and the Germany-led clusters, were more balanced on export and import of a variety of bilateral trades; the Brazil-led cluster (cl-4) had a relatively greater importance for the world exporting countries, while for the Czech-led cluster (cl-6) the opposite held true. The smaller clusters were either exporters or importers in a few specific trades. Since 2003, the Germany-led cluster has been balanced between export and import; the Japan \& China-led cluster was more important as an exporter, the US-led cluster as an importer.

\section{Figure 9 - Infomap flow by cluster, country and layer}

Figures refer to Infomap flow IN

Panel (a): Infomap flow by year and cluster.

All the other panels, Infomap flow percentage by year and by cluster, respectively,

Panel (b): by country, panel (c): by SITC code; panel (d): by trade flow. 
(b)

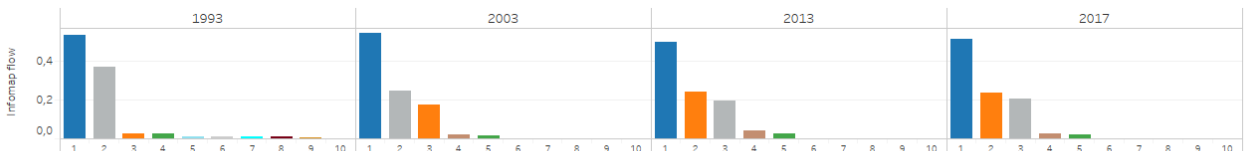

(c)
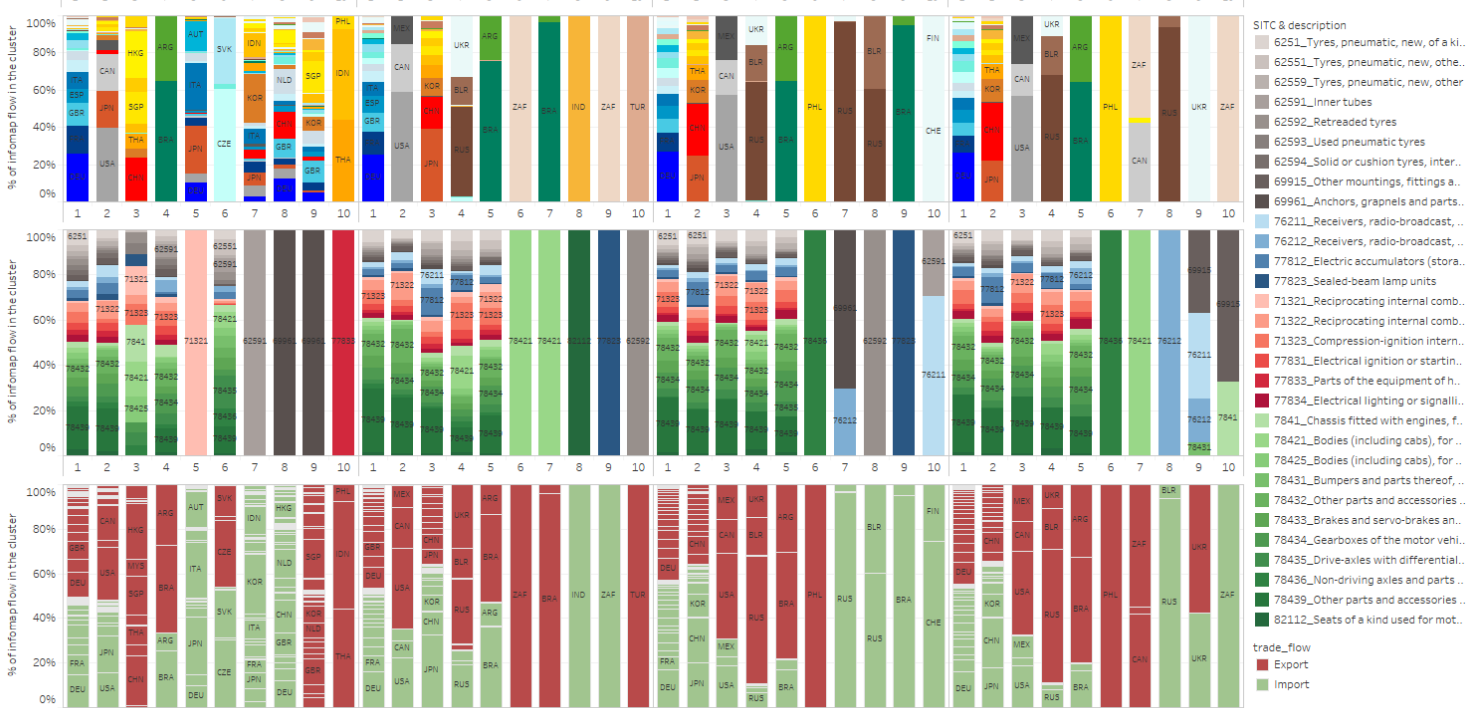

Source: Authors' elaboration on UN Comtrade International Trade Statistics Database

As we know, over the period 1993-2017, the main changes occurred because of NAFTA, which split the Pacific area into two distinct areas of trade: the East, in which Japan and China became dominant, together with South Korea and other Eastern Asian countries; and the West, with the US, Canada and Mexico, with the latter's importance increasing over the years at the expense of Canada. That preferential trade agreement gave rise to significant foreign direct investment in the US and in Mexico and Canada (Carreto Sanginés et al., 2021)).

5.3 Exploration of internal vs external flows and overlapping nodes across multilayer modules

Figure 11 shows the cross-cluster connections and the relative importance of countries in contributing to them. First, the share of Infomap flow generated by connections with other clusters increased for almost all clusters. Secondly, the countries providing the highest contribution in determining the meso-entities are also providing the highest contributions to cross cluster connections: in 2017, the top 50\% of the Infomap flow was determined by Germany, United States, China, Mexico, Japan, France, Spain. The leading countries in creating more connections among clusters than within clusters are South Korea, Russia, India, Brazil, Australia and South Africa ${ }^{27}$.

27 Figures by country can be browsed by navigating the online tool 
Figure 10 - Infomap flow within and between clusters of countries, by year, and by country

Countries ranked by Infomap flow in 1993

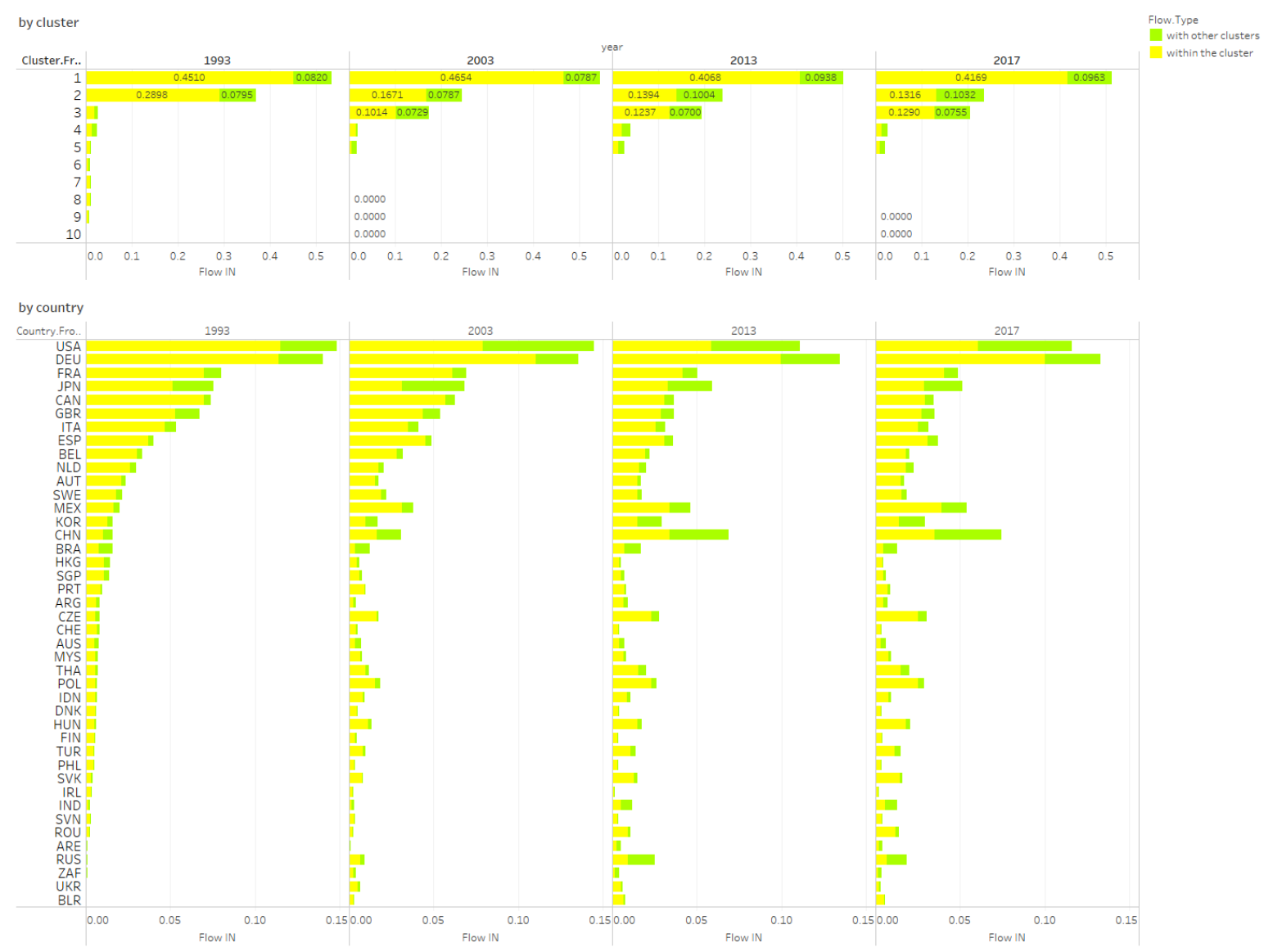

Source: Authors' elaboration on UN Comtrade International Trade Statistics Database

Focusing on the structure of clusters in terms of the contribution of exports and imports of the 30 commodities, the tree maps in Figure 11 show the overall size of the Infomap (percentages are computed by year and cluster on the sum of export and import Infomap flow).

While it is beyond the scope of this paper to provide a detailed comparison of all the different structures for each of the clusters, we note that:

- $\quad$ in 1993: the first two clusters were almost similar, but cluster 2 - US and Japan led - showed a greater flow-between value; while cluster 3, led by China, was characterized solely by export flows generated by all four groups of SITC codes. Cluster 6 (Czech-led) had a relatively larger share of flow- between clusters; it had a relatively larger share of imports of Electric and Electrical Parts. Clusters 5 (Japan-led) and 7 (South Korea-led), each characterized by one main group, largely connect countries within their clusters

- $\quad$ over the years, the first three clusters maintained a diversified composition of trade in components, both within and with other clusters: 
- $\quad$ in 2003 and 2017: cluster 7 was characterized by export of Miscellaneous Parts, but in 2003 it was led by Brazil while in 2017 it was led by South Africa.

Figure 11 - Treemap of Infomap flow within and between clusters, by cluster, year and group of components and parts

Selection of the first seven clusters in each year. Percentage by year and cluster

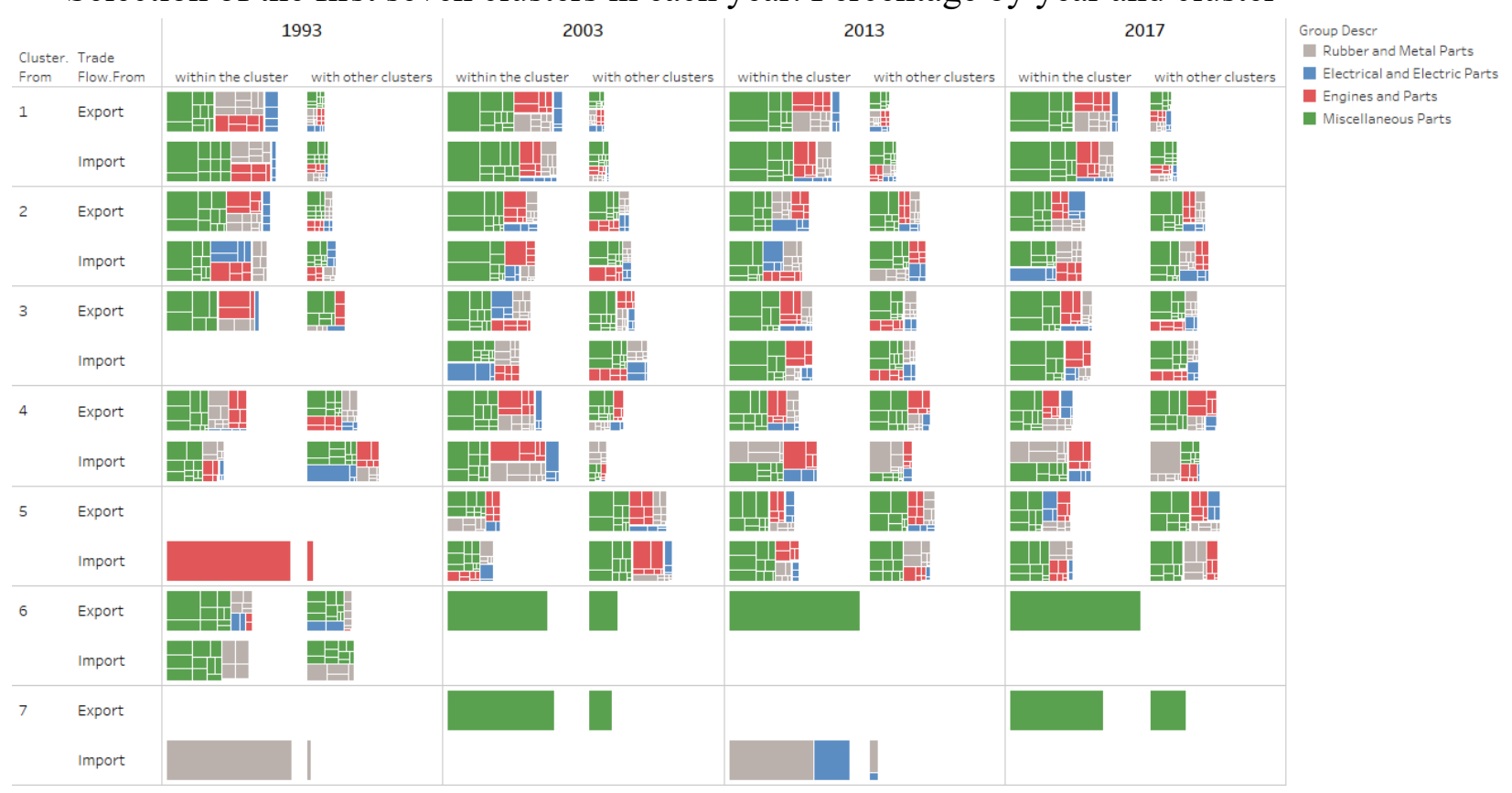

Source: Authors' elaboration on UN Comtrade International Trade Statistics Database

With regard to countries that overlap with other clusters, it is interesting to explore specific characteristics: do they trade more or fewer goods (quantities, number of items) than countries on a single cluster? Do they show persistence in their position as bridges, or are they absorbed by one of the clusters? Are they balanced in trades between clusters, or are they actually receiving most of their flow from a single cluster? In order to address these questions, we turn analysis from the Infomap flow to the trade shares. Having, with the Infomap algorithm, identified clusters and their determinants (which countries and which components are traded in exports and imports), and assessed the connections within clusters and between clusters, identifying which specific trade flows determine those results, we can proceed to process the flows within and between clusters (i.e., list of pairs state-nodes-from, state-nodeto) to produce results in terms of export and import shares, which we can now associate with the various clusters. These analyses will be presented in the following section.

\section{From Infomap flow to trade shares: patterns of trades by cluster}

We explore in detail the changes that have taken place in the trade networks of the main clusters, led respectively by Germany, China and the US. We pay special attention to the embedding of satellite clusters of countries (peripheries and semi-peripheries) within those 
clusters, with a focus on the impact of USMCA. Another focus is the groups making Engines and Parts, which include internal combustion engines (ICEs) and their components and parts, around which many changes will occur in the ongoing shift toward electric vehicles: the relative importance of countries in the various clusters will be evaluated to predict a direction of the impact of the reduction of trades on ICEs and their components and parts.

\subsection{Patterns of trades of the three main clusters}

To explore the structure and changes of the three main clusters we focus on export and import shares, by year and groups of SITC codes, within the cluster they belong to and with other clusters.

\section{The US-led cluster}

As already observed, the US-led cluster emerged as a cluster separate from Japan's after the introduction of NAFTA in 1994. This is clearly visible in Figure 12, where the countries are listed in decreasing order of their export shares (within cluster and with other clusters). In 1993, Japan's share of total export was $17.7 \%$, that of the US $16.2 \%$, while Canada and Mexico accounted for about $7 \%$ and $4.4 \%$ respectively; the trade share of the other 16 countries in this cluster were negligible.

In 1993, Japan and the US were trading with countries in the Germany-led cluster. Since 2003, the cluster structures its composition with the three countries belonging to NAFTA and their trade shares have been mainly within the cluster. US trades across clusters account for the $10.5 \%$ of its total import, against $8.6 \%$ within the cluster, the main traded components are in the Miscellaneous Parts group. Canada and Mexico trade mainly within the cluster, both for export (respectively, 2.6\% and 6.9\%) and for import (respectively, 4.4\% and 4.3\%).

The center and right panels of Figure 12 show the trade shares of the three NAFTA countries by groups of components. In 1993, with Japan embedded in this cluster, the main trades outside the cluster were with the Germany-led cluster for most components. For the US, the main trades with the Brazil-led cluster were in both Rubber and Metal Parts (accounting, respectively $10.1 \%$ of export and $23.1 \%$ of import) and in Electrical and Electric Parts (accounting for $18.5 \%$ of export and $37.9 \%$ of import). With respect to Engines and parts, the US was trading with the China-led cluster (accounting for $5.8 \%$ of its export and $4.7 \%$ of its imports). While Canada was largely relying on Argentina for its imports of Electrical and Electric Parts (46.3\%), Mexico imported from the Brazil-led cluster 23.7\% of Engine and Parts and 50\% of Miscellaneous Parts.

The trade patterns changed with the introduction of NAFTA and, by 2017, the largest share of export and import - for the three countries and for all the groups of components - were with the China-led cluster. Only Mexico had a significant share of trade with Brazil (in Engine and Parts, that accounted, respectively, for $22.8 \%$ of its export and $10.9 \%$ of its import

of that group of components). Colors in the right panel highlight - for the US, Canada and 
Mexico - patterns of export and import trade shares that differ by group of components. China is the main partner for each of the three countries when it comes to import of Electrical and Electric Parts (respectively: US 40.8\%, Canada 39.7\%, and Mexico 41.2). China is the main partner of the US, with the exception of Engine and parts, which nonetheless accounts for a relatively large share of the US imports of Engine and Parts (26.1\%). With regard to Mexico, $42.4 \%$ of Engine and Parts are imported from the Germany-led cluster, and mainly from Germany (16.5\%) and Hungary (12.3\%). Trade relations with the China-led cluster are dominated by China and Japan, which account, respectively, for 18\% and $11.9 \%$ of Mexico's imports of Engines and Parts.

Figure 12 - US-led cluster - export and import shares, by year and groups of SITC codes

Main countries ranked by export share in 1993. Other 16 countries accounted in 1993 for about $3.5 \%$ of export share. Since 2003 the other two countries in the cluster accounted for a negligible share of export.

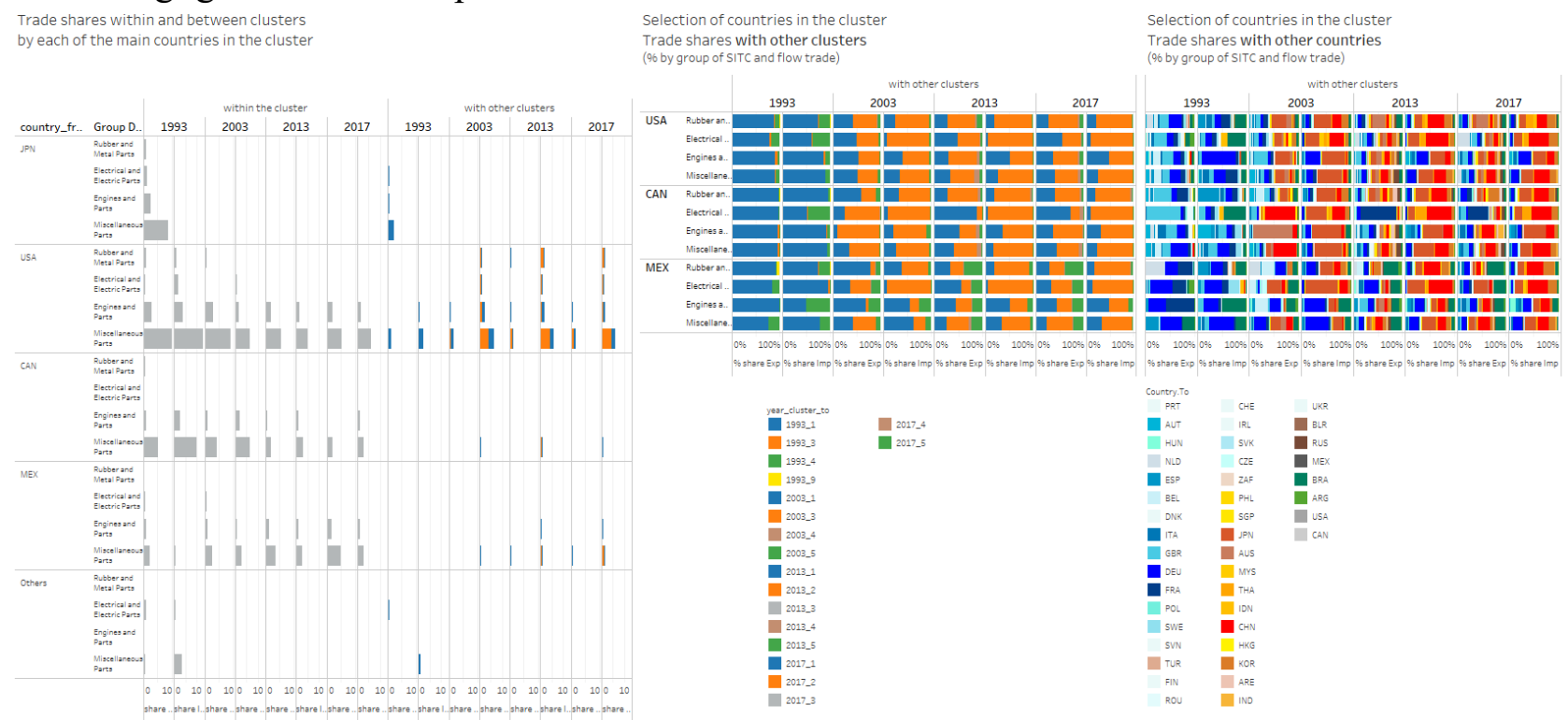

Source: Authors' elaboration on UN Comtrade International Trade Statistics Database

$\underline{\text { The Germany-led cluster }}$

The Germany-led cluster has been changing its internal structure, embedding another minor cluster led by the Czech Republic (see Figure 3), which was structured around trading more with countries also outside the cluster in 1993. In Figure 13, the overall share of export and of import highlights the growing importance of the Czech Republic, Hungary, Slovakia and Poland, which supplanted the countries that were structuring this cluster in 1993, namely, France, Italy, Spain, and the United Kingdom. 
Figure 13 - Germany-led cluster: export and import shares, by year, and cluster

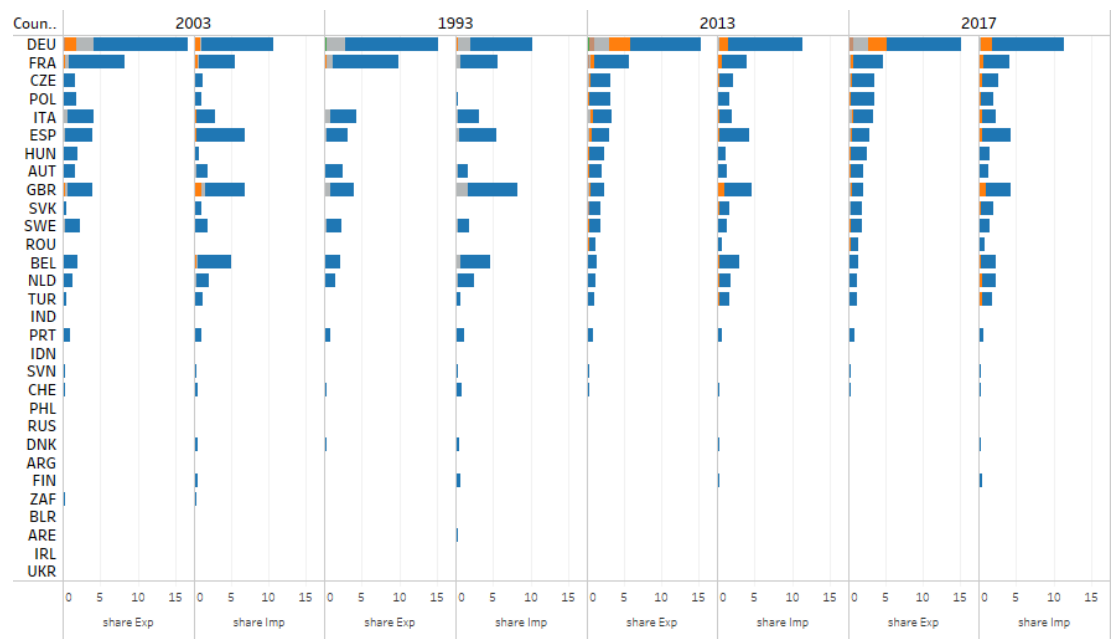

Source: Authors' elaboration on UN Comtrade International Trade Statistics Database

Figure 14 shows the trade shares of Germany and the four Central Eastern European countries. Export and import shares for each country refer to trading with other clusters (left panel) and with countries in those clusters (right panel). We find that Germany and Poland have significant and increasing trade relations with the China-led cluster, and mainly with China itself, while South Korea is the main partner for the Czech Republic and Slovakia. The trade patterns of this cluster with the US-led one are obviously mirrored to those observed in the previous paragraph. It is worth noting that a significant share of trade, in 2013 and 2017, took place between countries in the Russia-led cluster, mainly Russia, in particular for the exports of Slovakia in all groups of components but Rubber and Metal Parts (for which the US is the main partner, with $46.5 \%$ of Slovakia's exports of those components). 
Figure 14 - Germany-led cluster - export and import shares, by year and groups of SITC codes, trade shares within the cluster they belong to and with other clusters

Selected countries in the cluster ranked by export share in 1993.

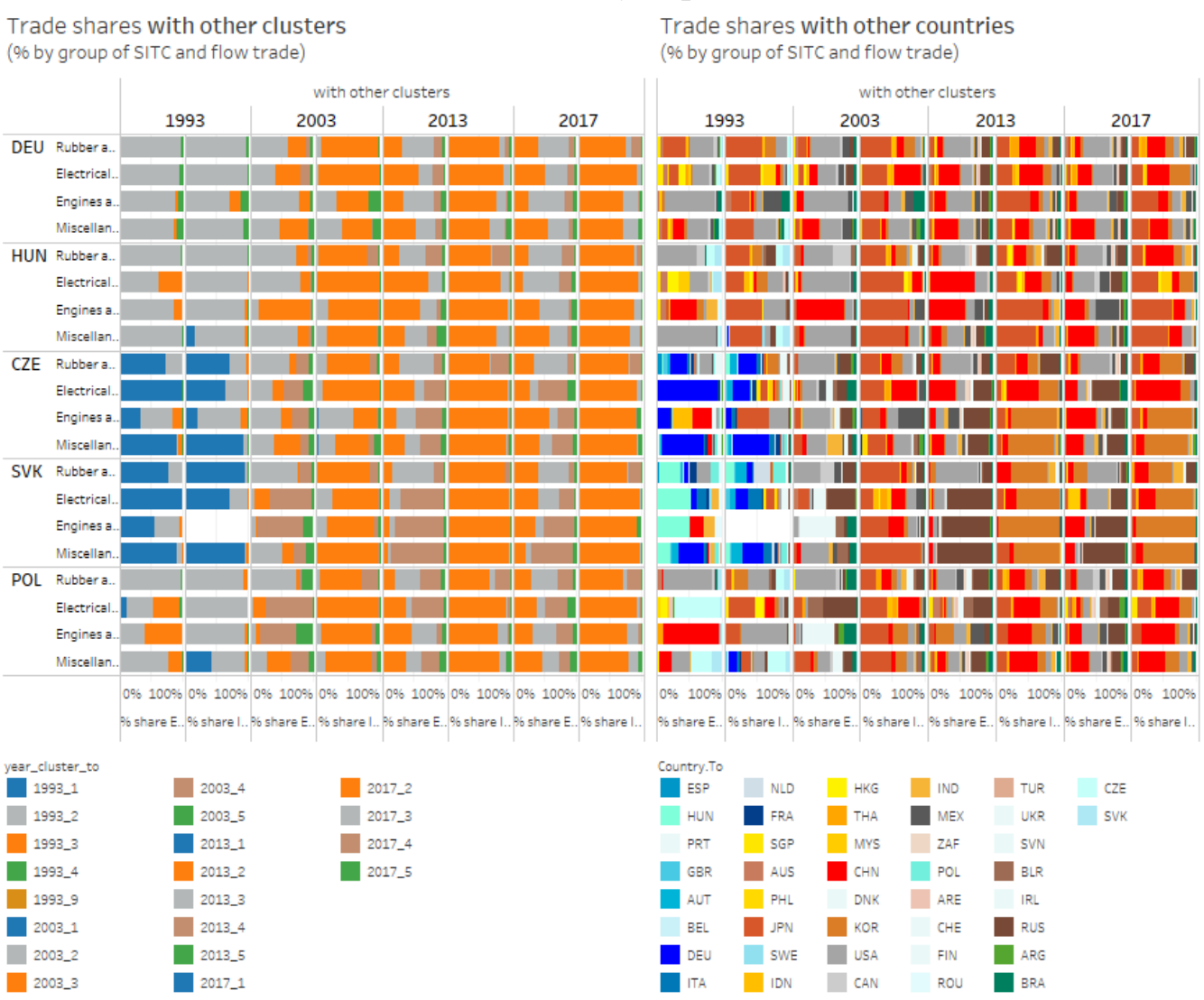

Source: Authors' elaboration on UN Comtrade International Trade Statistics Database

The Japan and China-led cluster

The Japan and China-led cluster (Figure 15) highlights the increasing importance of South Korea, Thailand, and of Hong Kong, India, Indonesia, Malesia, Singapore and also Australia, closely embedded in this cluster.

The pattern of trade with other clusters is obviously in line with the above observations on the US-led cluster and the Germany-led cluster. With respect to exports, the US (commented on above) is very important for China; Brazil and Argentina are important partners for Thailand and Indonesia, while Russia is a very important partner for several countries in the cluster: in 2017, Japan exported to the Russia-led cluster 12.6\% of Rubber and Metal Parts, South Korea and China exported, respectively, $14 \%$ and 22.2\% of Engines and Parts, and 9\% and $6 \%$ of Miscellaneous Parts. With respect to imports, the relevance of the Germany-led cluster shows in the trade connection across several groups of components imported not only from Germany but also from the other countries in the Germany-led cluster.

In terms of trade shares, the smaller countries belonging to this cluster - Thailand, Hong Kong, India, Indonesia Malaysia - have different patterns of trade shares and, as from 2003 
moved towards more balanced trade shares with the US-led cluster and the Germany-led cluster.

Figure 15 - Japan and China-led cluster in 2017 - export and import shares and groups of SITC codes, within the cluster they belong to and with other clusters

Countries ranked by export share in 1993.

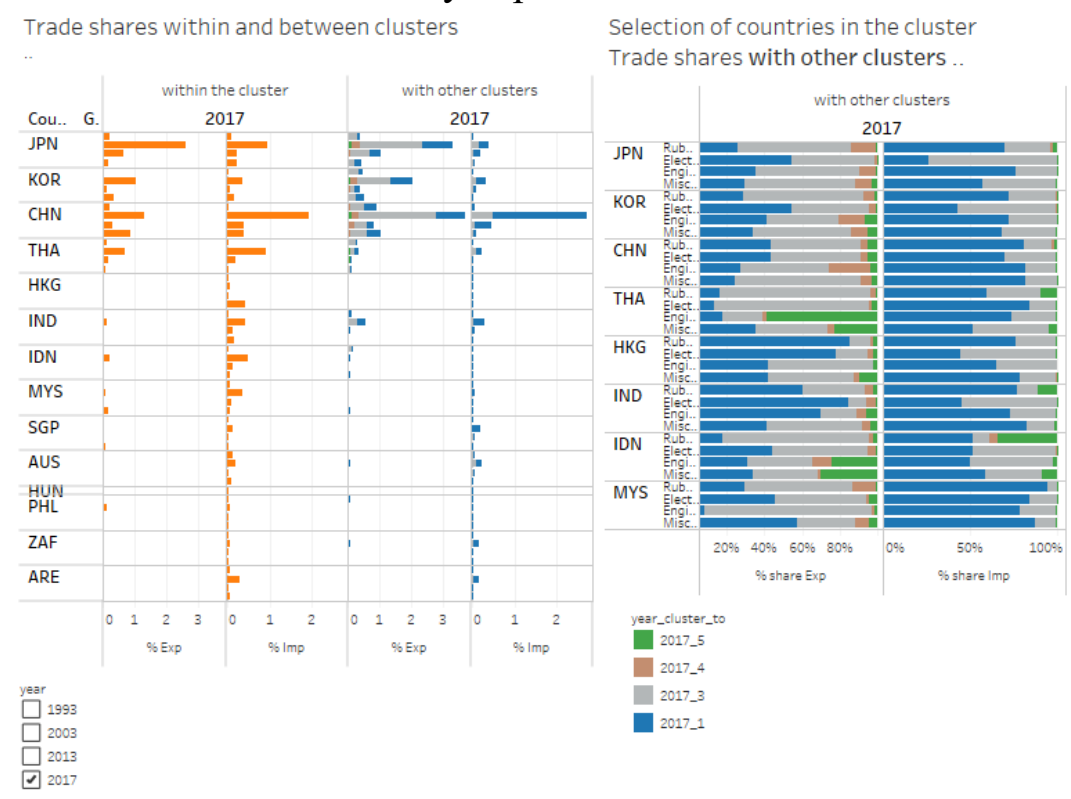

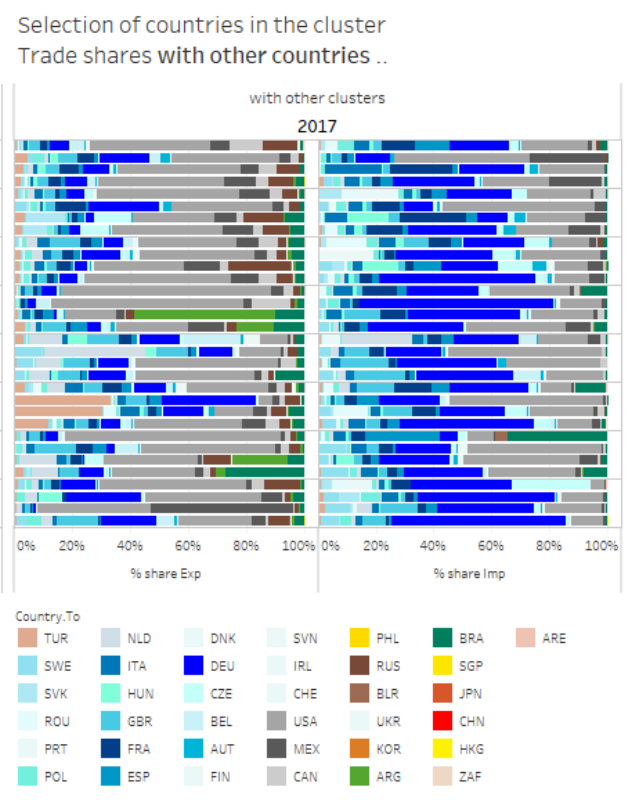

Selection of countries in the cluster

Source: Authors' elaboration on UN Comtrade International Trade Statistics Database

\subsection{From vehicles with internal combustion engines (ICE) to electric vehicles}

It is estimated that with the transition from the internal combustion engine (ICE) to the electric engine the average number of powertrain components could drop from 1,500 to just 230 (Schulte, 2020). In this section we use the results of the analysis conducted so far to gauge the potential effects of the electrical transition on trade, that is, which countries and which bilateral trade flows could be more negatively affected, though we cannot say yet which new trade flows, competences and countries will emerge. To this end, we take all the components required to convert the engine's power into movement (namely, engine, transmission, driveshaft, differentials, axles): basically, anything connecting the engine to the wheels.

Thus, we focus on the six SITC codes in the group Engines and parts ${ }^{28}$. Their share in the total exports of the four groups of automotive components and parts is quite stable over the years. However, though still accounting for the largest part of total trade, its share of withincluster trade declines (from 15.4\%, in 1993, to 12.6\% in 2017) (fig. 16). Moreover, the dynamics of the sub-groups within Engines and Parts (fig.16, part b) varies considerably, reflecting the changes in location and product that the sector underwent over the period.

28 The list of items classified in the SITC codes 713.21, 713.22 and 713.23 is available in Annex 8. 
The overall impact on trade of the transition from ICE to electric will affect the leading countries: almost half of the total export of Engines and Parts is generated by 6 countries (Germany, United States, China, Japan, Mexico and South Korea) (Fig. 17). Though the largest part occurs within clusters, almost one third of those exports go to countries in other clusters (a feature in line with what we observed above about inter-cluster connections). ${ }^{29}$ This means that the transition risks disrupting a large part of transactions within each cluster, especially in the ones headed by US and Germany.

On the import side, we see that in 2017 the US was the largest importer of Engines and Parts from countries in other clusters (1.7\%) and imported a similar share from within its clusters. Conversely, Germany imported more from countries within the cluster than from countries in other clusters. Finally, in line with the strategy of its car makers, Japan imported small shares from other countries, mainly from the Germany-led cluster.

This preliminary study suggests that the transition could entail a big restructuring in trade flows, especially within clusters, which could affect more heavily the integrated peripheries, without that exempting the leading countries in their trade between countries.

Figure 16 - Export trade shares (total, within and between clusters), by group of automotive components and parts, and by SITC code of Engine and Parts, 1993, 2003, 2013, 2017
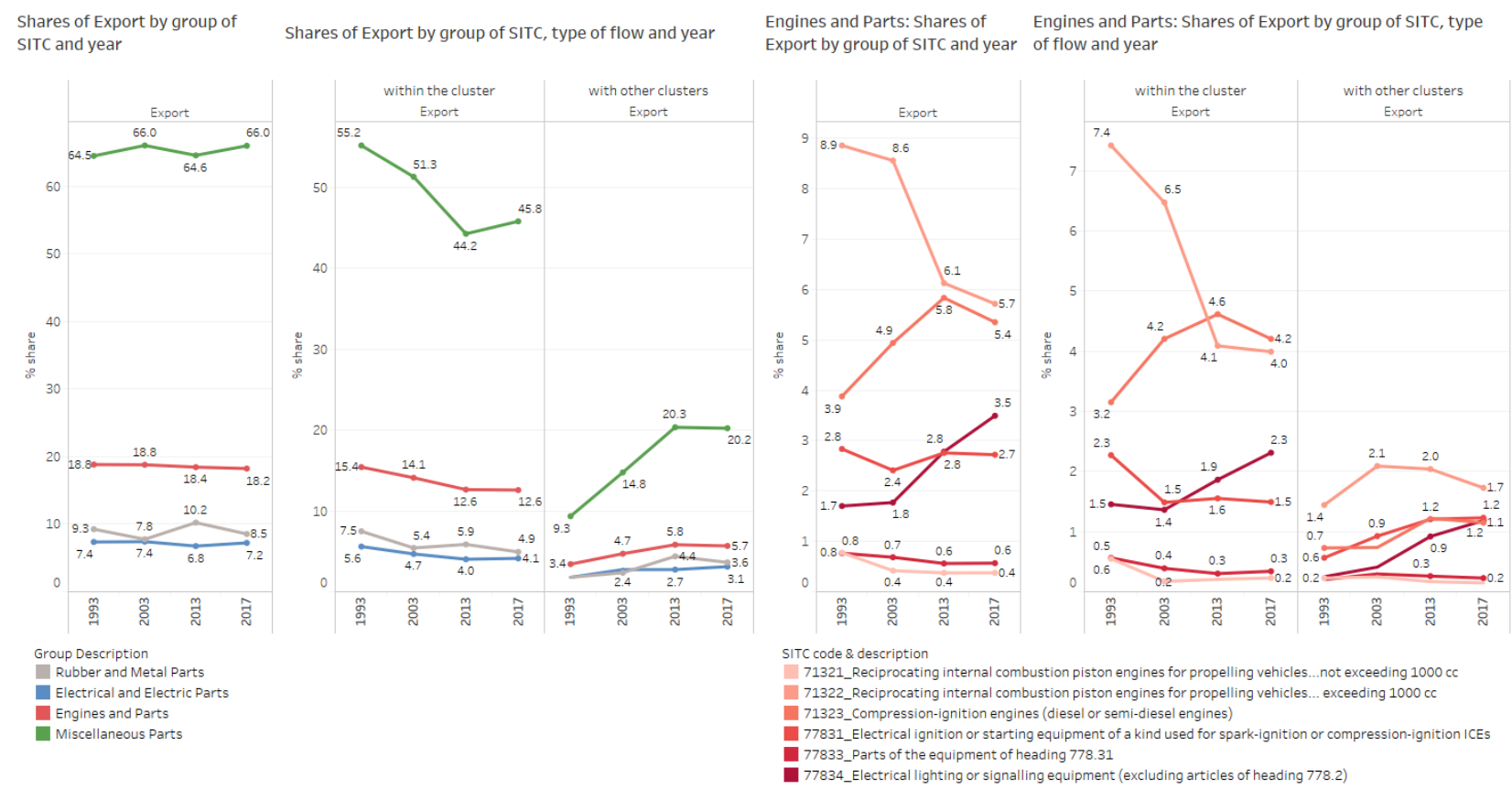

Source: Authors' elaboration on UN Comtrade International Trade Statistics Database

29 Explore on line data on internal combustion engines: shares of export and import by country, SITC code and year [flows within and between clusters (part B)]. 
Figure 17 - ICEs, 2017: Trade Shares of Export and Import by countries within the cluster and in other clusters

SITC codes: 713.21, 713.22, 713.23, 778.31, 778.33 and 778.34. Countries are ranked by total share in each panel
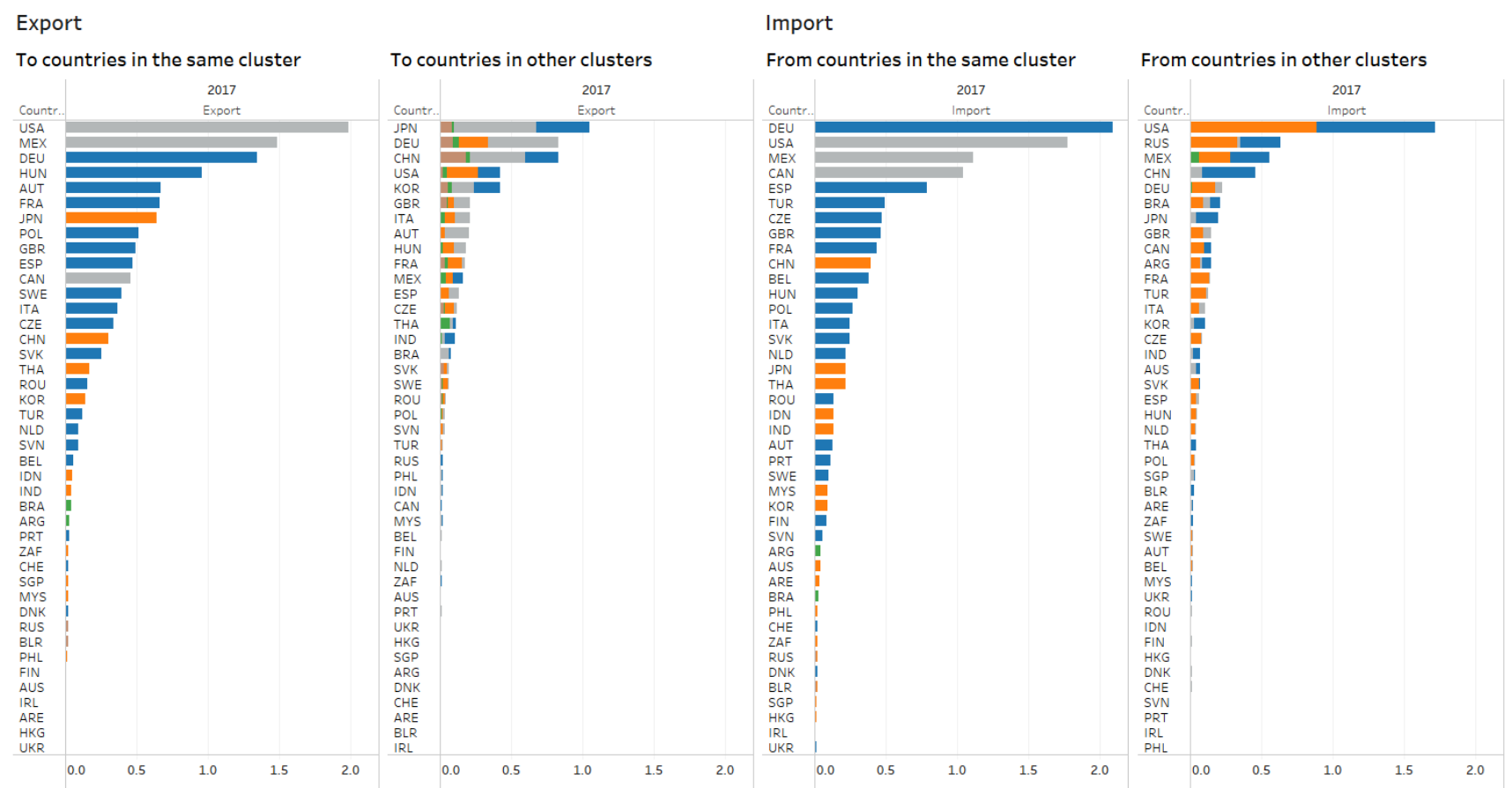

Source: Authors' elaboration on UN Comtrade International Trade Statistics Database

\section{Discussion and next steps in the ongoing research project}

Automotive OEMs and suppliers are facing unprecedented supply chain disruptions. The microchip crisis has made it more difficult to produce vehicles, but the pandemic has disrupted nearly every aspect of the global supply chain, as the lack of even a single component may be enough to halt production. The effects of the pandemic have been magnified by decades of delocalization and fragmentation of production, resulting in long and complex value chains, together with lean production, whereby inventories are kept low to reduce costs. The shortages have led to reconsidering the need to shorten value chains, diversify supplies and/or identify those components that need to be re-shored to prevent dependency on overseas sources for critical parts. Moreover, with the new world of mobility and electrification accelerated by the pandemic, a whole segment of the value chain producing parts and components for the internal combustion engine will have to restructure or downsize. Batteries and chips are on the forefront of the OEMs' worries.

With automotive global value chains in such turmoil, the definition of the pre-pandemic situation presented in the paper can prove an indispensable starting point for analysis of the possible repercussions of the current technological and geo-political transition on geographical clusters and the sectorial specializations of the main regions and countries. In the 
economic literature on international trade, study of the automotive global value chains has been addressed using network analysis, focusing on the centrality of geographical regions and countries while largely overlooking the contribution of countries' bilateral trades in components and parts to the structuring of the subnetwork of countries and their specific position in the overall trade network.

In this paper, we analyze the trade networks of 30 groups of automotive components and parts between 42 countries (accounting for $98 \%$ of world trade flows in those items) over a period of 25 years. Using the Infomap multilayer clustering algorithm, we identify clusters of countries and their specific trades in the automotive international trade network, highlighting the relative importance of each cluster and the interconnections between them, as well as the contribution of countries and of components and parts in the clusters.

It should be noted that clusters are not derived from examination of the trade flows within and outside the geographical areas, as is current practice in the literature, but by analyzing recurring patterns of bilateral trades between countries worldwide. Drawing the aggregate bilateral trade flows (Figure 2), we identify a clear structure in the main subnetworks of trade flows with an evident geographical base: one subnetwork is centered in Europe, while another, initially centered in the Pacific area (embracing countries in East Asia, the US and Canada), changed with China's entry in the WTO in 1994 and implementation of NAFTA. Several other smaller subnetworks, not specifically linked to any of the main subnetworks, have emerged and changed in structure and size over time.

The analytical value added of the multilayer clustering method lies in identification of clusters over time and measurement of the changes in trade flows within and across clusters which led to the changing configuration of the clusters. Focusing on the changes in the geography of trade relations, we find denser and more hierarchical clusters generated, respectively, by Germany's trade relations with EU countries, the US preferential trade agreements with Canada and Mexico, and the upsurge of China. Focusing on the composition of trade, we observe that the largest clusters show a similar structural composition of trade. It should be noted, however, that although the most detailed statistics grouped under 30 SITC codes specific to automotive production encompass almost ten thousand different components and parts, the quality and characteristics of the various components and parts are likely to differ significantly, implying a considerable increase in the actual number of different items traded. The Infomap multilayer analysis singles out which SITC codes of components and parts determined the relative positions of countries in the various clusters as well as of the smaller clusters that turn out to be highly specialized with different trade orientation. Changes over time in the relative positions of countries and their specializations in multilateral trades are detailed for the main clusters and can be explored in detail for all the clusters using the online tool Tableau ${ }^{30}$. Over the years, the regionalization of trade thickens (many small clusters of

30 Selected Figures and Tables marked with the symbol 垶 can be browsed on line on Tableau Public, with respect to data and community detection (part A), and to flows within and between clusters (part B). 
countries disappear), but the links between clusters also increase significantly. Measuring the growing and appreciable importance of connections between the clusters over time represents an original contribution to the literature on regionalization of trade, which generally reserves little attention to this phenomenon.

The economic implications of inter-regional connections have become evident during the COVID-19 pandemic, with supply chains severely affected by lockdown in countries where suppliers were located and for which there were no substitutes within the clusters. The issue of redesigning the supply chain entered the agenda of carmakers and debates on national/local sovereignty, together with the need to reconsider redundancy as a more efficient solution - compared to just-in-time or free-pass production methods - and logistics and transport as possible causes of bottlenecks in supply chains. In the short term, the impact of these events has been shifted on to price increases along the supply chain or has affected the cars' performance (as in the case of cars delivered in reasonable time and price but with fewer microchip devices). In the medium term, reorganization of the automotive industry will be marked by the carmakers' commitment to comply with the requirements of $\mathrm{CO} 2$ emissions, durability of batteries, and smarter mobility - issues subject to heated debate and on which there is no agreement between the countries (as emerged in COP26). The analysis presented in the paper presents a picture of the trade conditions before the changes induced by the COVID-19 pandemic and electric and sustainable mobility, offering a benchmark for analysis of the changes post-transition.

The paper also affords an opportunity to analyze the impact of trade treaties in changing geopolitical scenarios. The focus on the US and Mexico on the one hand, and Germany and the Central and Eastern European countries (CEE: Czech Republic, Hungary, Poland, Slovakia) on the other, drives the comparative analysis. Data on the US-led cluster sheds light on the major shift in international trade driven by NAFTA (in particular the triangulation of trades occurring via Mexico), which could be compared with the effects of the boost to direct foreign investment in Mexico expected under the new USMCA agreement.

Different perspectives emerge on the relations between the core countries and their partners (semi peripheries and peripheries) in the various clusters. In the US-led cluster, closer connections within the cluster went hand-in-hand with a reversal of the relative importance of the two main partners, Canada and Mexico. Conversely, the structural changes within the Germany-led cluster highlight the strategy of the German OEMs aimed at integrating the CEE countries in ever closer connections, each of them still maintaining trade relations outside the Germany-led cluster, thus strengthening its connections with world trade.

Finally, the detailed analysis focused on individual components and parts casts light on the trade patterns related to the production of internal combustion engines (ICEs). The results show the different dynamics of parts and components for ICEs over time, and the potential impact of the transition to electric vehicles on the main countries exporting ICEs. It is not possible, however, to estimate, from trade data alone, the potential impact on their production 
structure. Future trade flows in components and parts related to electric mobility will emerge in relation to the new, rapidly changing technologies and the geography of trades that national interests and company strategies will shape.

Two strands of research stem from the results of multilayer analysis of trade.

First, the international trade network is only one of the various interrelated networks that should be considered for a full understanding of the trade pattern: networks of technologies, competences and organizations, regional trade agreements and preferential trade arrangements are intertwined with the trade flows operated by TNCs (car manufacturers and Tier 1 suppliers), which in turn affect countries' trading. Analysis of those networks will call for ad hoc investigation into the dynamics of change which occurred in the automotive value chains, with a specific focus on who produces what and where.

A complementary area of research has to do with the impact of electric mobility. The main exporting countries, as well as an array of the smaller ones, will be affected by the steady reduction of components entering the production of vehicles using internal combustion engines, which will be progressively discontinued to comply with the new regulations enforced in Europe, the US and China by 2030. Although new components will be needed, their production will not necessarily be located in the same places where ICEs and their components are now being produced. Analysis of the potential impact of these changes will call for more detailed classification of trade statistics and information on the production structure of the countries at present involved in the export of ICE components and parts, and of those countries that will be specializing in components and parts for electric mobility. 


\section{References}

Amighini, A., \& Gorgoni, S. (2014a). The International Reorganization of Auto Production. The World Economy, 37(7), 923-952. https://doi.org/10.1111/twec.12091

Amighini, A., \& Gorgoni, S. (2014b). The International Reorganization of Auto Production. The World Economy, 37(7), 923-952. https://doi.org/10.1111/twec.12091

Barigozzi, M., Fagiolo, G., \& Mangioni, G. (2011). Identifying the community structure of the international-trade multi-network. Physica A: Statistical Mechanics and Its Applications, 390(11), 2051-2066. https://doi.org/10.1016/j.physa.2011.02.004

Boccaletti, S., Bianconi, G., Criado, R., del Genio, C. I., Gómez-Gardeñes, J., Romance, M., Sendiña-Nadal, I., Wang, Z., \& Zanin, M. (2014). The structure and dynamics of multilayer networks. Physics Reports, 544(1), 1-122. https://doi.org/10.1016 /j.physrep.2014.07.001

Carreto Sanginés, J., Russo, M., \& Simonazzi, A. (2021). Mexico's Automotive Industry: A Success Story? Institute for New Economic Thinking Working Paper Series, 166. https://doi.org/10.36687/inetwp166

De Backer, K., \& Miroudot, S. (2012). Mapping global value chains. Paper Prepared for the Final WIOD Conference: Causes and Consequences of Globalization, Groningen, The Netherlands, April 24-26, 2012., Groningen. http://www.wiod.org/conferences/groningen/Paper_DeBacker_Miroudot.pdf

De Domenico, M., Granell, C., Porter, M. A., \& Arenas, A. (2016). The physics of spreading processes in multilayer networks. Nature Physics, 12(10), 901-906. https://doi.org/10.1038/nphys3865

De Domenico, M., Lancichinetti, A., Arenas, A., \& Rosvall, M. (2015). Identifying Modular Flows on Multilayer Networks Reveals Highly Overlapping Organization in Interconnected Systems. Physical Review X, 5(1). https://doi.org/10.1103/PhysRev X.5. 011027

De Domenico, M., Solé-Ribalta, A., Cozzo, E., Kivelä, M., Moreno, Y., Porter, M. A., Gómez, S., \& Arenas, A. (2013). Mathematical Formulation of Multilayer Networks. Physical Review X, 3(4), 041022. https://doi.org/10.1103/PhysRevX.3.041022

DRC, Development and Reform Commission, Ministry of Science and Technology, Ministry of Finance and Industry, \& Ministry of Finance of the Peoples's Republic of China. (2019). Notice on Further Improving the Financial Subsidy Policy for the Promotion and Application of New Energy Vehicles. http://jjs.mof.gov.cn/zhengwuxinxi/zhengcefagui/ 201 903/t20190326_3204190.html

Edler, D., Bohlin, L., \& Rosvall, M. (2017). Mapping Higher-Order Network Flows in Memory and Multilayer Networks with Infomap. Algorithms, 10(4), 112. https://doi.org/ 10.3390/a10040112

European Commission. (2019). The European Green Deal, COM/2019/640 final, EURLex-52019DC0640-EN-EUR-Lex. https://eur-lex.europa.eu/legal-content/EN/TXT/?qid=1596443911913\&uri=CELEX\%3A52019DC0640\#document2

Fagiolo, G., Reyes, J., \& Schiavo, S. (2009). The World-Trade Web: Topological Properties, Dynamics, and Evolution. Physical Review E, 79(3), 036115. https://doi.org/10.1103 /PhysRevE.79.036115 
Fortunato, S., \& Hric, D. (2016). Community detection in networks: A user guide. Physics Reports, 659, 1-44. https://doi.org/10.1016/j.physrep.2016.09.002

Gorgoni, S., Amighini, A., \& Smith, M. (2018a). Automotive international trade networks: A comparative analysis over the last two decades. Network Science, 6(4), 571-606. https://doi.org/10.1017/nws.2018.18

Gorgoni, S., Amighini, A., \& Smith, M. (2018b). Automotive international trade networks: A comparative analysis over the last two decades. Network Science, 6(4), 571-606. https://doi.org/10.1017/nws.2018.18

Hausmann, R., Hidalgo, C. A., Bustos, S., Coscia, M., Chung, S., Jimenez, J., Simões, A., Yildirim, M. A. (2011). The Atlas of economic complexity: Mapping paths to prosperity. Center for International Development, Harvard University: Harvard Kennedy School : Macro Connections, MIT : Massachusetts Institute of Technology. http://www.hks.harvard.edu/centers/cid/publications/featured-books/atlas

Helper, S., \& Sako, M. (2010). Management innovation in supply chain: Appreciating Chandler in the twenty-first century. Industrial and Corporate Change, 19(2), 399-429. https://doi.org/10.1093/icc/dtq012

Hirschman, A. O. (1977). A generalized linkage approach to development, with special reference to staples. Economic Development and Cultural Change, 25, 67.

Hirschman, A. O. (1980). National power and the structure offoreign trade (Vol. 105). Univ of California Press.

Hunkar, D. (2019). The Global Auto Industry is an Oligopoly | TopForeignStocks.com. https://top foreignstocks.com/2019/10/27/the-global-auto-industry-is-an-oligopoly/

Kivela, M., Arenas, A., Barthelemy, M., Gleeson, J. P., Moreno, Y., \& Porter, M. A. (2014). Multilayer networks. Journal of Complex Networks, 2(3), 203-271. https://doi.org/ 10.1093/comnet/cnu016

Mangioni, G., Jurman, G., \& De Domenico, M. (2018). Multilayer flows in molecular networks identify biological modules in the human proteome. IEEE Transactions on Network Science and Engineering.

Newman, M., E.J., \& Girvan, M. (2004). Finding and evaluating community structure in networks. Physical Review E, 69, 26-113.

Piccardi, C., \& Tajoli, L. (2018). Complexity, centralization, and fragility in economic networks. PLOS ONE, 13(11), e0208265. https://doi.org/10.1371/journal.pone.0208265

Rosvall, M., \& Bergstrom, C. T. (2008). Maps of random walks on complex networks reveal community structure. Proceedings of the National Academy of Sciences, 105(4), 1118-1123. https://doi.org/10.1073/pnas.0706851105

Rosvall, M., \& Bergstrom, C. T. (2011). Multilevel compression of random walks on networks reveals hierarchical organization in large integrated systems. PloS One, 6(4), e18209.

Schulte, J. (2020, September 2). How EVs Will Reshape the Auto Supply Chain. https://www. sme.org/technologies/articles/2020/september/mvyb-supply-chain/ 


\section{ANNEXES}

\section{Annex 1 Figures on automotive sector}

Source: Authors elaboration on data of the International Organization of Motor Vehicle Manufacturers, available at https://www.oica.net/production-statistics/

Figure A1 - Share of production of vehicles by country, 2003, 2013, 2017

Countries listed according to their share in 2003

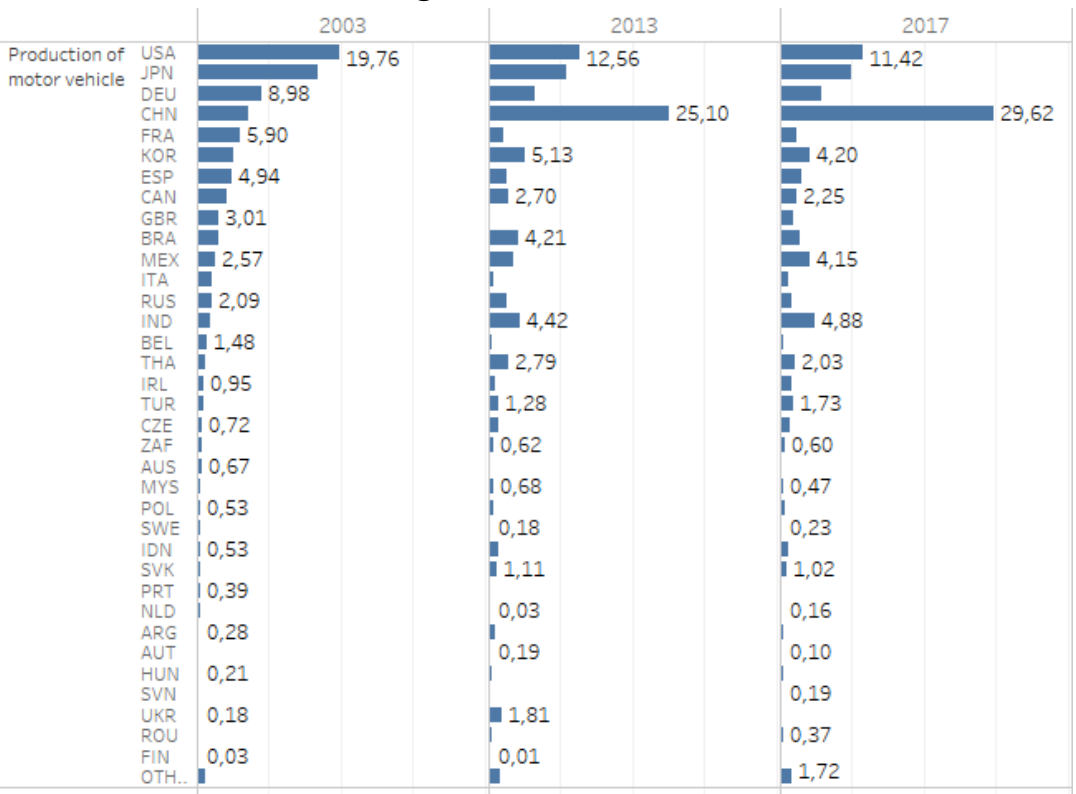




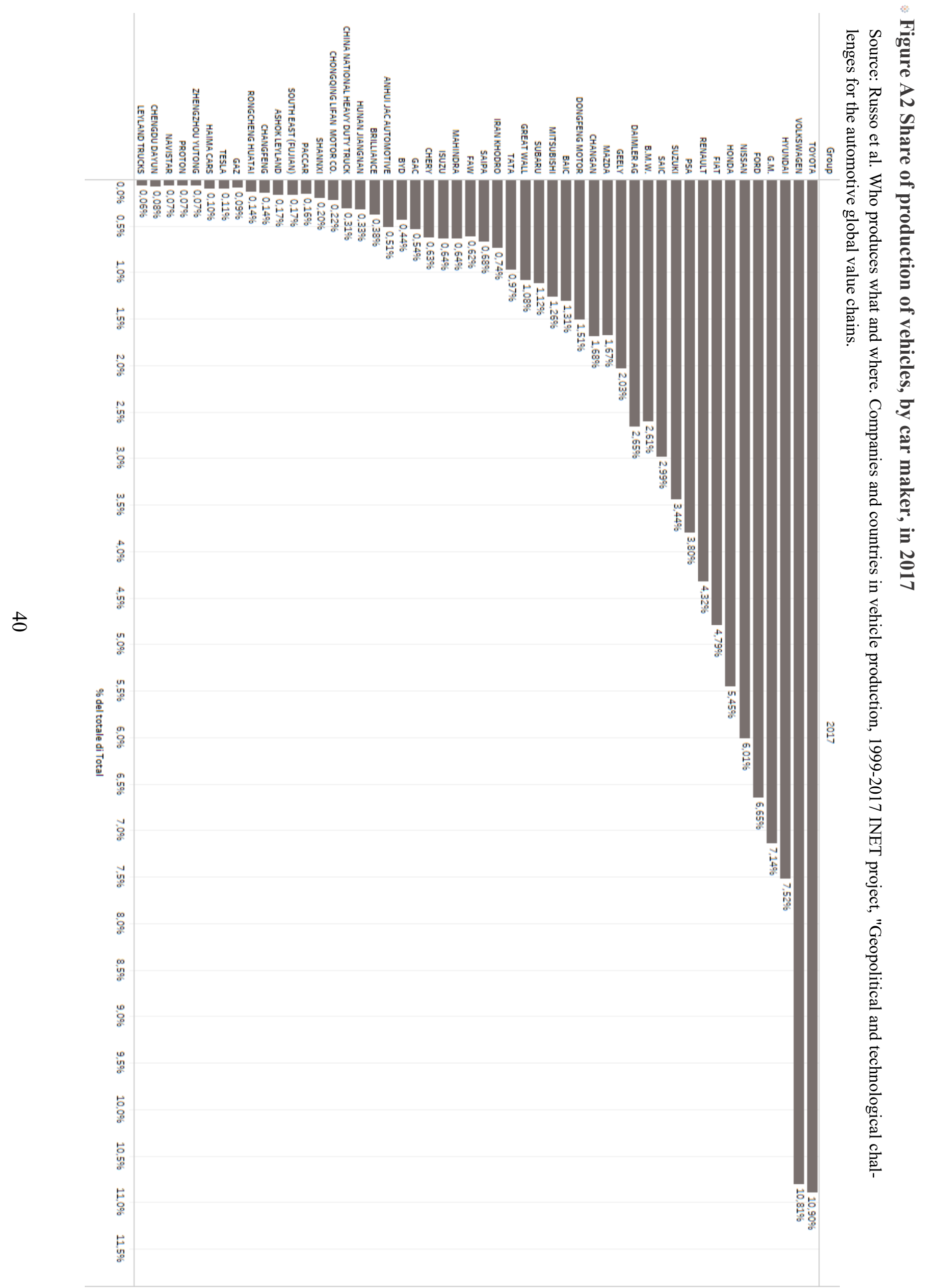


Table A1 - Export and import of automotive components and parts and of motor cars and other motor vehicles, 1993, 2003, 2013, 2017 (billion USD at current price)

\section{Export}

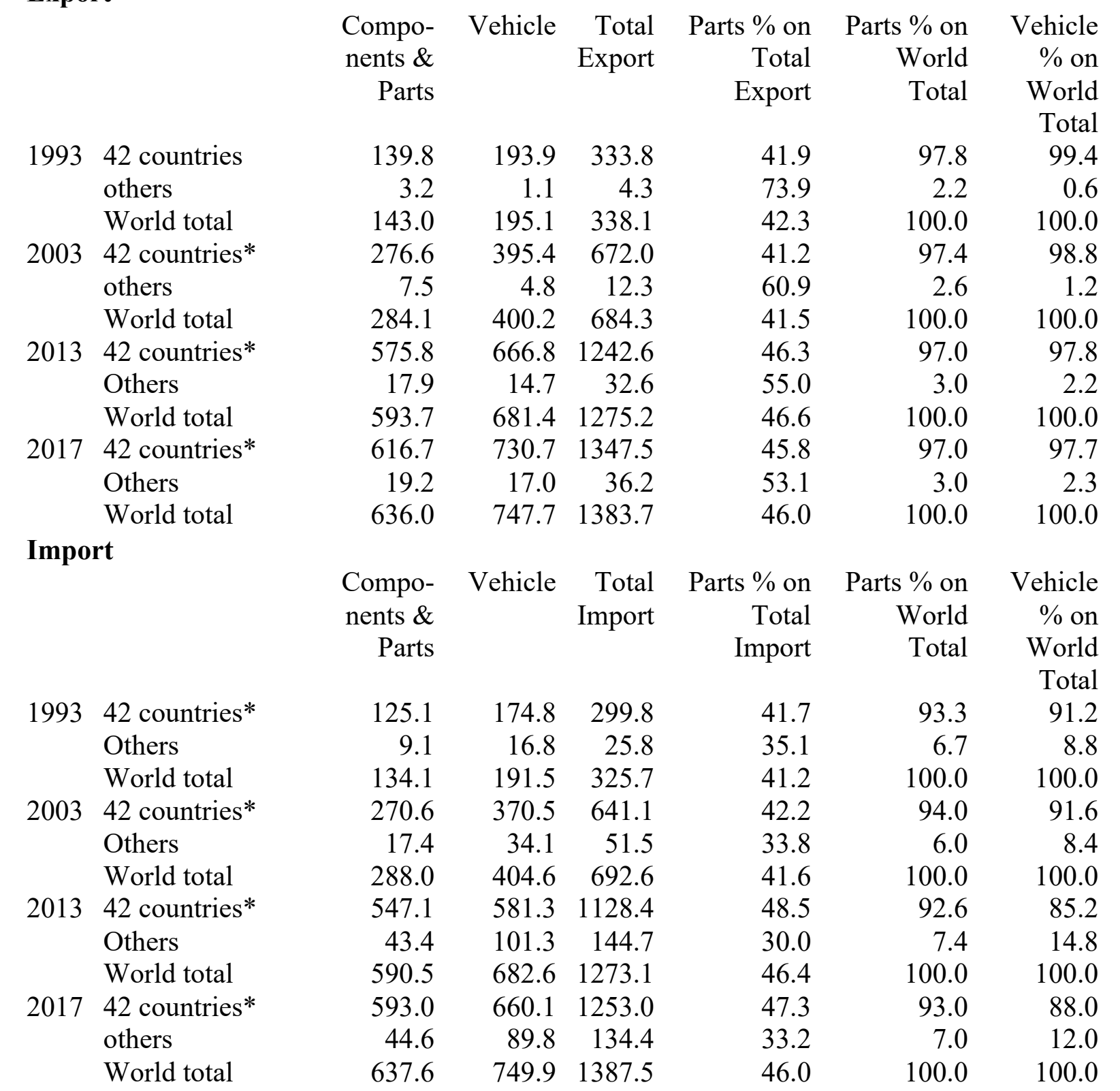

Values, for each year are the three-year average of trade in the year in analysis, the year before and the following year.

Components \& Parts:

SITC rev. 3 codes:

$6251,62551,62559,62591,62592,62593,62594,69915,69961,76211,76212,77812,77823,71321,71322$, 71323, 77831, 77833,

77834, 7841, 78421, 78425, 78431, 78432, 78433, 78434, 78435, 78436, 78439, 82112

Vehicle:

SITC rev.3 code 781: Motor cars and other motor vehicles principally designed for the transport of persons (other than public-transport type vehicles), including station wagons and racing cars

42 countries:

ARG, AUS, AUT, BLR, BEL, BRA, CAN, CHN, HKG, CZE, DNK, FIN, FRA, DEU, HUN, IND, IDN, IRL, 
ITA, JPN, MYS, MEX, NLD, PHL, POL, PRT, KOR, ROU, RUS, SGP, SVK, SVN, ZAF, ESP, SWE, CHE, THA, TUR, UKR, ARE, GBR, US

Data source: UN Comtrade 


\section{Annex 2 Details on SITC Rev.3 codes}

The details below make clear why it is not significant to consider data at the 2-digit level, given that too many items that are not relevant are included. For each code, the number of 3digit codes for the 4-digit and 5-digit codes we select from SITC Rev.3 are listed.

\section{Table A2 - Two-digit aggregation of the selected codes}

(n.e.s.: not elsewhere specified)

62 Rubber manufactures, n.e.s. has 3 sets of 3-digit codes: we select only 625 Rubber tires, tire treads or flaps \& inner tubes

69 Manufactures of metal, n.e.s. : has 8 sets of 3-digit codes: we select only 699 Manufactures of base metal, n.e.s.

76 Telecommunication and sound recording apparatus has 4 sets of 3-digit codes: we select only 762 Radio-broadcast receivers, whether or not combined

77 Electrical machinery, apparatus and appliances, n.e.s. has 8 sets of 3-digit codes: we select only 778 Electrical machinery \& apparatus, n.e.s.

71 Power generating machinery and equipment has 6 sets of 3-digit codes: we select only 713 Internal combustion piston engines, parts, n.e.s.

77 Electrical machinery, apparatus and appliances, n.e.s. has 8 sets of 3-digit codes: we select only 778 Electrical machinery \& apparatus, n.e.s.

78 Road vehicles has 6 sets of 3-digit codes: we select only 784 Parts $\&$ accessories of vehicles of 722, 781, 782, 783

82 Furniture and parts thereof has 1 set of 3-digit codes: we select only 821 Furniture \& parts

Table A3 below lists the products included in item 784.39 (SITC Rev.3) 
Table A3 - List of products included in item 784.39 (SITC Rev.3)

"other parts and accessories of the motor vehicles of groups 722, 781, 782" (see table above)

- Casings, clutch, for road motor vehicles (excl. motor cycles) or tractors 1

- $\quad$ Casings, steering-gear, for road motor vehicles (excl. motor cycles) or tractors1

- $\quad$ Clutches, non-magnetic (excl. integral parts of engines), for road motor vehicles (excl. motor cycles) or tractors 1

- $\quad$ Connecting-rods for brakes or clutches of road motor vehicles (excl. motor cycles) or tractors 1

- $\quad$ Discs, wheel, for road motor vehicles (excl. motor cycles) or tractors1

- $\quad$ Exhaust-pipes for tractors1

- $\quad$ Hub-caps for road motor vehicles or tractors1

- $\quad$ Levers, clutch, for road motor vehicles (excl. motor cycles) or tractors1

- $\quad$ Levers, gear-change, for road motor vehicles (excl. motor cycles) or tractors1

- $\quad$ Levers, handbrake, for road motor vehicles (excl. motor cycles) 1

- $\quad$ Levers, steering, for road motor vehicles (excl. motor cycles) or tractors1

- Linings, clutch, mounted, for road motor vehicles (excl. motor cycles) or tractors1

- $\quad$ Mufflers for road motor vehicles (excl. motor cycles) or tractors1

- $\quad$ Pedals, accelerator, brake and clutch, for road motor vehicles or tractors1

- $\quad$ Plates, clutch, for road motor vehicles (excl. motor cycles) or tractors1

- $\quad$ Racks and pinions, steering, for road motor vehicles1

- $\quad$ Radiators for road motor vehicles or tractors1

- $\quad$ Rims, wheel, for road motor vehicles (excl. motor cycles) and tractors1

- $\quad$ Axles, steering-wheel, for road motor vehicles or tractors1

- $\quad$ Servo-steering mechanisms for road motor vehicles1

- $\quad$ Shock absorbers, for road motor vehicles (excl. motor cycles) or tractors (excl. tractors of heading 744.11)1

- $\quad$ Silencers for road motor vehicles (excl. motor cycles) or tractors1

- $\quad$ Spokes, wheel, for road motor vehicles (excl. motor cycles) or tractors1

- $\quad$ Steering gear (and parts thereof), for road motor vehicles (excl. motor cycles) or tractors 1

- $\quad$ Steering-column tubes, for road motor vehicles (excl. motor cycles) or tractors1

- $\quad$ Steering-columns for road motor vehicles (excl. motor cycles) or tractors1

- $\quad$ Steering-wheels for road motor vehicles or tractors1

- $\quad$ Suspension parts (excl. springs) for road motor vehicles (excl. motor cycles)1

- $\quad$ Tailpipes for road motor vehicles (excl. motor cycles) 1

- $\quad$ Tanks, fuel, for road motor vehicles (excl. motor cycles) or tractors1

- $\quad$ Tie-rods, steering knuckle, for road motor vehicles or tractors1

- $\quad$ Torsion bars for road motor vehicles or tractors1

- $\quad$ Tracks and sets of wheels for tracked road motor vehicles1

- $\quad$ Tracks for track-type tractors 1

- Wheel covers for road motor vehicles or tractors1

- Wheels, road, whether or not fitted with tyres, for road motor vehicles (excl. motor cycles) or tractors 1

The SITC 72,78, 79 codes encompass machineries and vehicles for which components and 
parts cannot be disentangled by the final product in which they are used 
Table A4 - List of SITC codes in items 722, 781, 782

motor vehicles of groups

code description

72 Specialized machinery

721 Agricultural machinery (excluding tractors) \& parts

722 Tractors (excluding those of $71414 \& 74415$ )

78 Road vehicles

781 Motor vehicles for the transport of persons

782 Motor vehicles for transport of goods, special purposes

783 Road motor vehicles, n.e.s.

784 Parts \& accessories of vehicles of 722, 781, 782, 783

785 Motorcycles \& cycles

786 Trailers \& semi-trailers

79 Other transport equipment

791 Railway vehicles \& associated equipment

792 Aircraft \& associated equipment; spacecraft, etc.

793 Ships, boats \& floating structures 


\section{Annex 3 List of countries and commodities under analysis}

Table A5 - List of the selected 42 countries: continental region, area, country name, Isoalpha3 code color

\begin{tabular}{|c|c|c|c|c|}
\hline \multirow{2}{*}{$\begin{array}{l}\begin{array}{l}\text { continental_ } \\
\text { regions }\end{array} \\
\text { Africa }\end{array}$} & \multirow{2}{*}{$\begin{array}{l}\text { Area } \\
\text { Africa }\end{array}$} & \multirow{2}{*}{$\begin{array}{l}\text { Country } \\
\text { South Africa }\end{array}$} & \multicolumn{2}{|c|}{$\begin{array}{l}\text { ISO-alpha3 } \\
\text { code }\end{array}$} \\
\hline & & & ZAF & - \\
\hline \multirow[t]{5}{*}{ Americas } & Central America & Mexico & MEX & $\boldsymbol{\square}$ \\
\hline & \multirow{2}{*}{$\begin{array}{l}\text { Northern } \\
\text { America }\end{array}$} & Canada & CAN & - \\
\hline & & USA & USA & $\square$ \\
\hline & \multirow[t]{2}{*}{ South America } & Argentina & ARG & $\boldsymbol{\square}$ \\
\hline & & Brazil & BRA & $\boldsymbol{\square}$ \\
\hline \multirow[t]{12}{*}{ Asia } & \multirow[t]{4}{*}{ Eastern Asia } & China & $\mathrm{CHN}$ & $\boldsymbol{\square}$ \\
\hline & & China, Hong Kong SAR & HKG & - \\
\hline & & Japan & JPN & $\boldsymbol{\square}$ \\
\hline & & Rep. of Korea & KOR & - \\
\hline & \multirow{5}{*}{$\begin{array}{l}\text { South-eastern } \\
\text { Asia }\end{array}$} & Indonesia & IDN & - \\
\hline & & Malaysia & MYS & - \\
\hline & & Philippines & PHL & 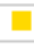 \\
\hline & & Singapore & SGP & 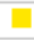 \\
\hline & & Thailand & THA & $\square$ \\
\hline & Southern Asia & India & IND & 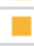 \\
\hline & \multirow[t]{2}{*}{ Western Asia } & Turkey & TUR & - \\
\hline & & United Arab Emirates & ARE & 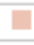 \\
\hline \multirow[t]{23}{*}{ Europe } & \multirow[t]{8}{*}{ Eastern Europe } & Belarus & BLR & $\boldsymbol{\square}$ \\
\hline & & Czechia & CZE & - \\
\hline & & Hungary & HUN & E \\
\hline & & Poland & POL & - \\
\hline & & Romania & ROU & 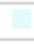 \\
\hline & & Russian Federation & RUS & $\boldsymbol{\square}$ \\
\hline & & Slovakia & SVK & - \\
\hline & & Ukraine & UKR & - \\
\hline & \multirow[t]{5}{*}{ Northern Europe } & Denmark & DNK & 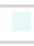 \\
\hline & & Finland & FIN & 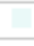 \\
\hline & & Ireland & IRL & L \\
\hline & & Sweden & SWE & E \\
\hline & & United Kingdom & GBR & $\square$ \\
\hline & \multirow[t]{4}{*}{ Southern Europe } & Italy & ITA & $\boldsymbol{\square}$ \\
\hline & & Portugal & PRT & L \\
\hline & & Slovenia & SVN & 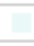 \\
\hline & & Spain & ESP & $\boldsymbol{\square}$ \\
\hline & \multirow[t]{6}{*}{ Western Europe } & Austria & AUT & $\boldsymbol{\square}$ \\
\hline & & Belgium & BEL & - \\
\hline & & France & FRA & $\boldsymbol{\square}$ \\
\hline & & Germany & DEU & $\boldsymbol{\square}$ \\
\hline & & Netherlands & NLD & - \\
\hline & & Switzerland & $\mathrm{CHE}$ & 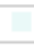 \\
\hline Oceania & No... 7 anland & Australia & AUS & $\square$ \\
\hline
\end{tabular}




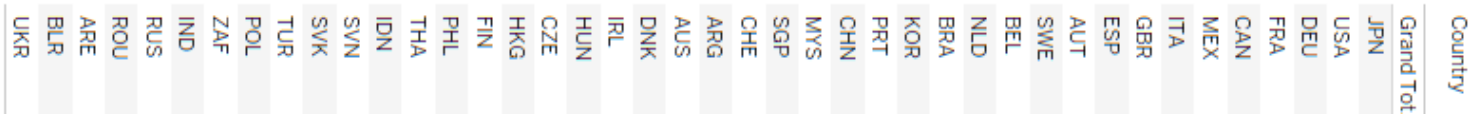

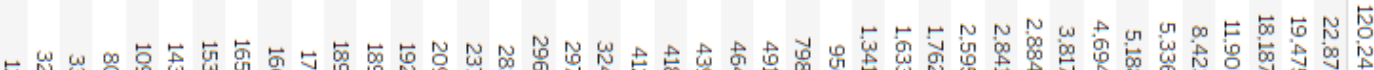
选

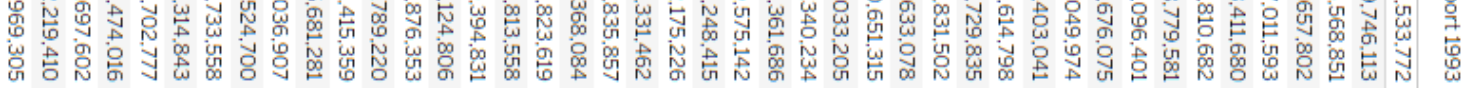

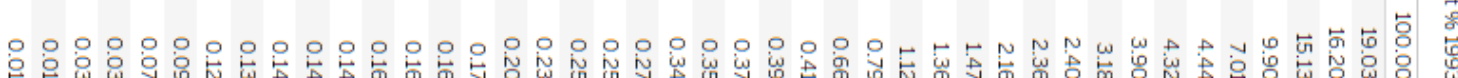
势

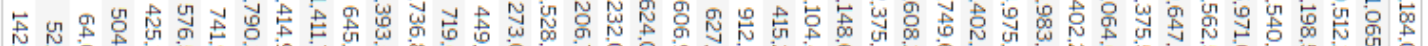

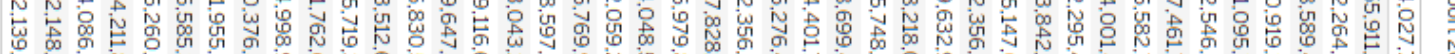

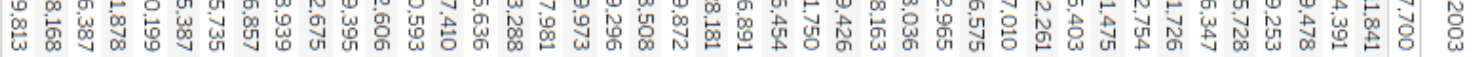

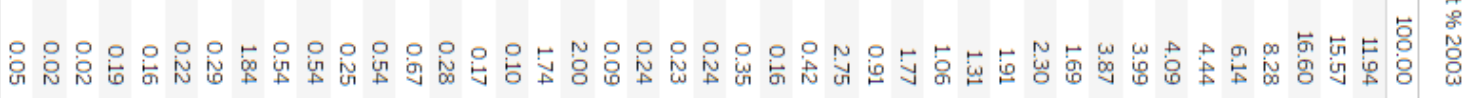

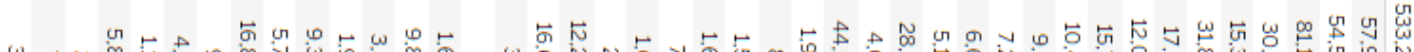

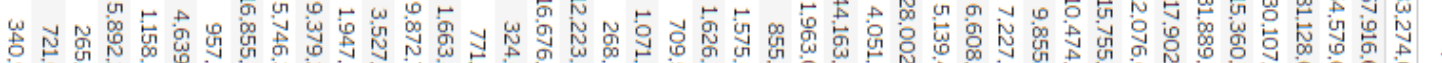

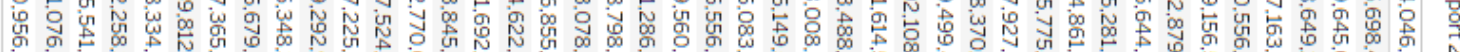

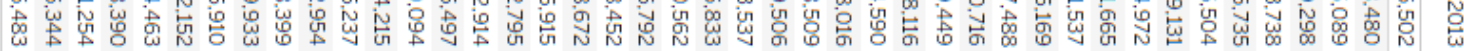

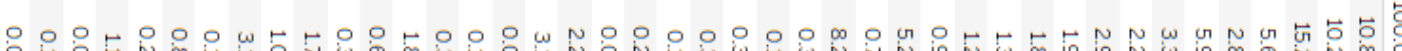

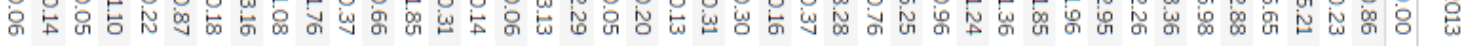

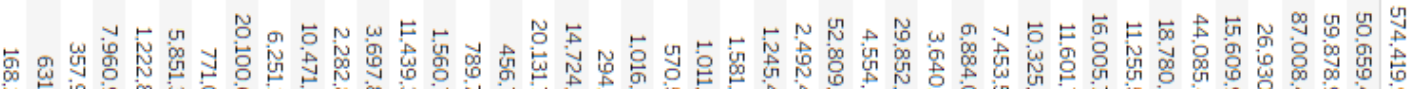
N

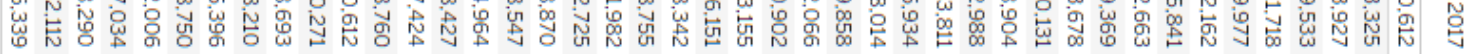

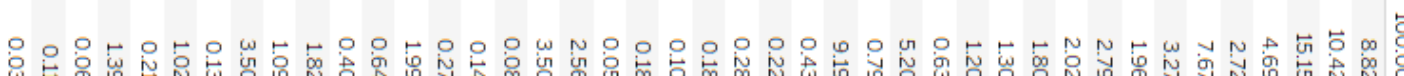

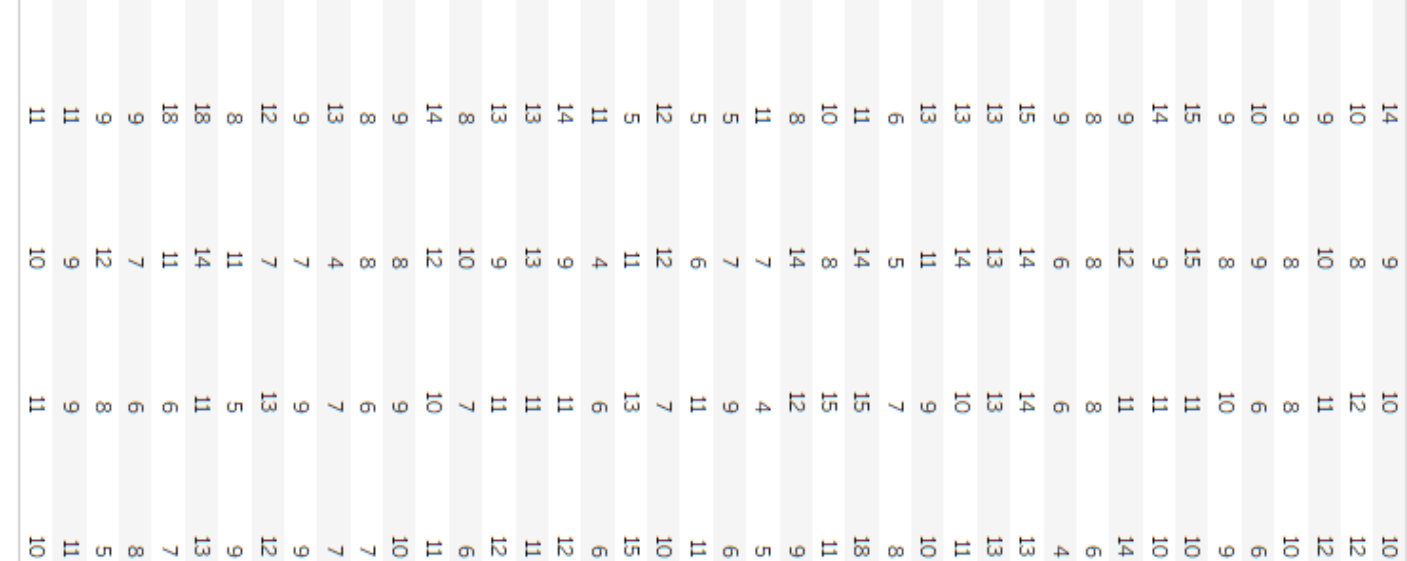

西 


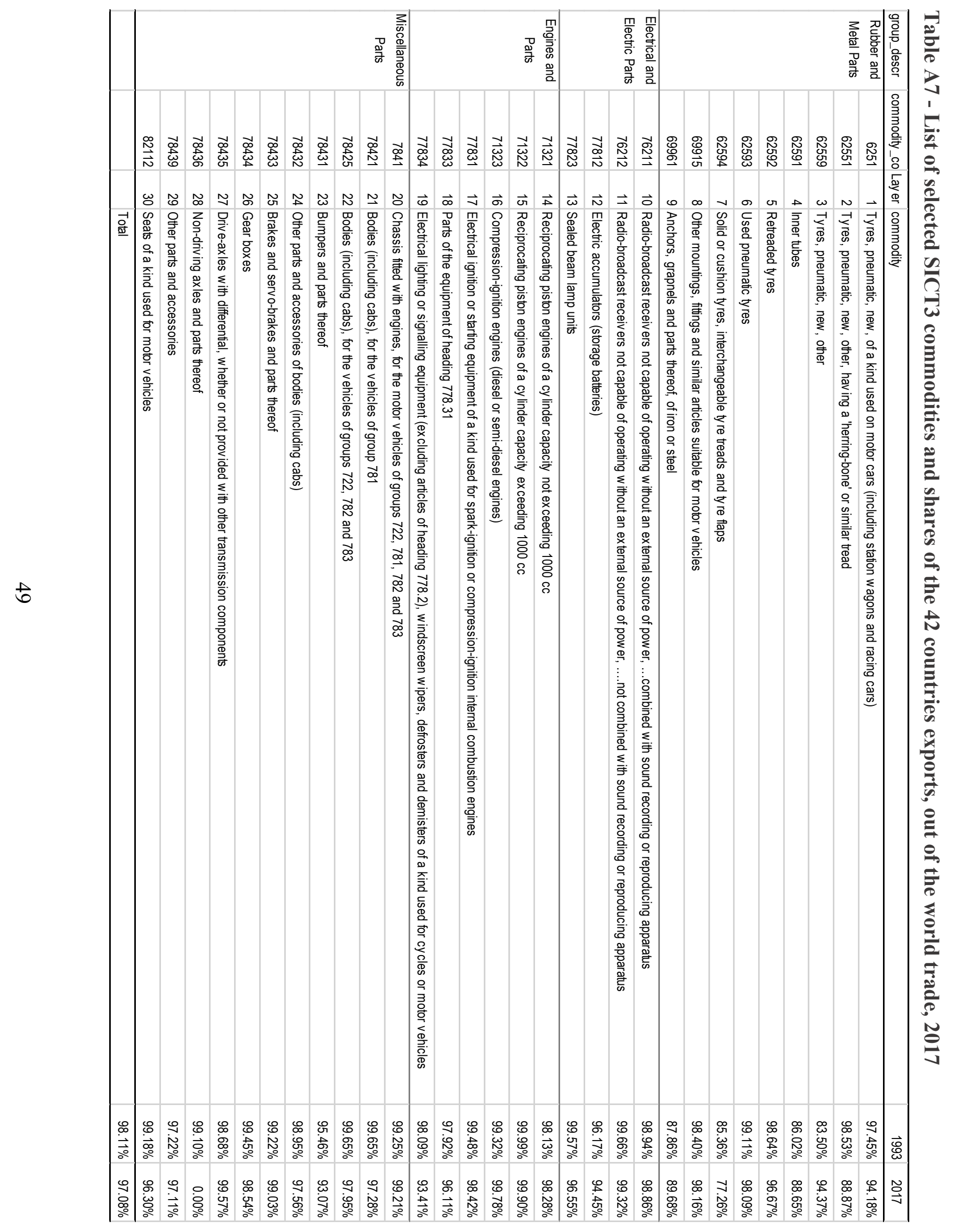




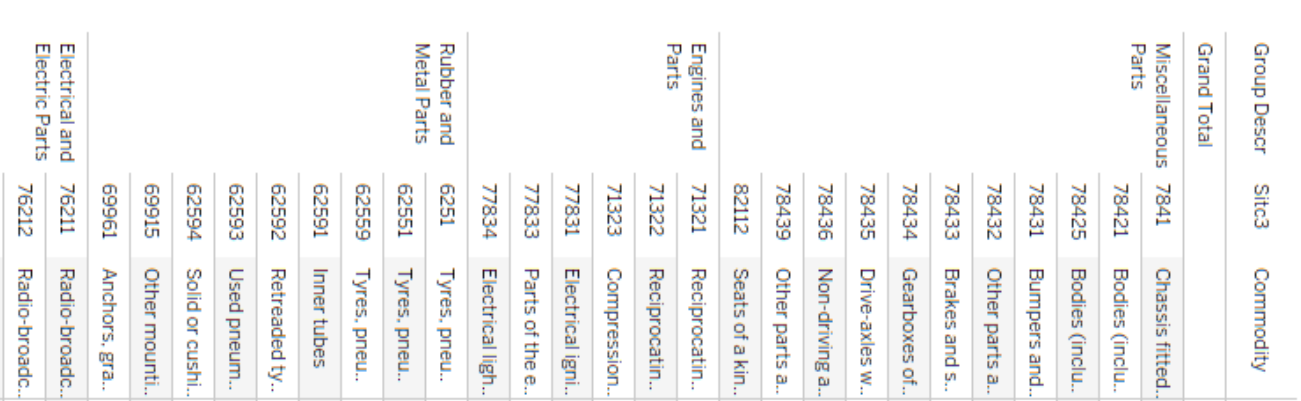

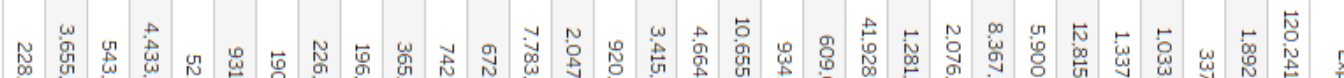

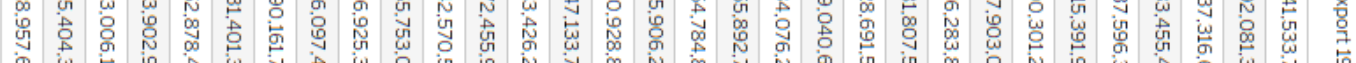

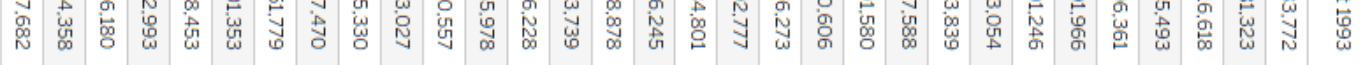

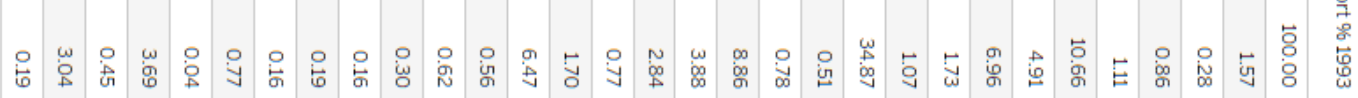

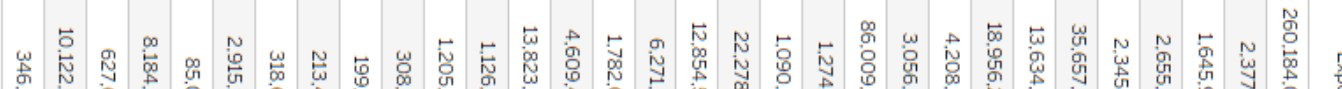

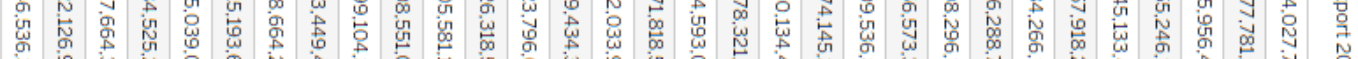

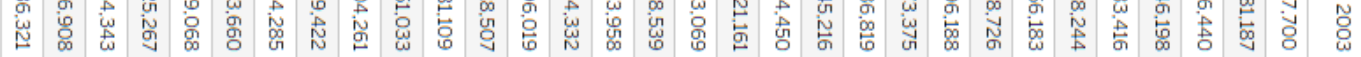

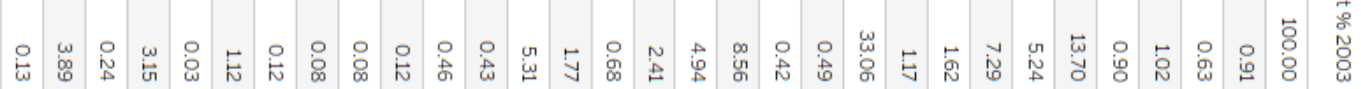

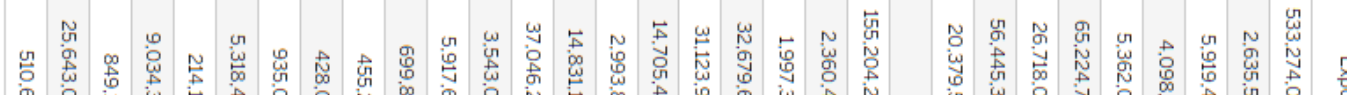

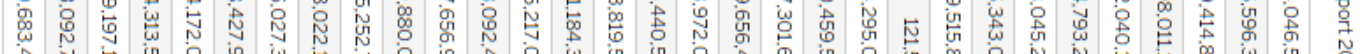

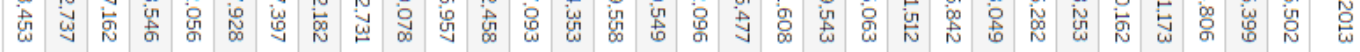

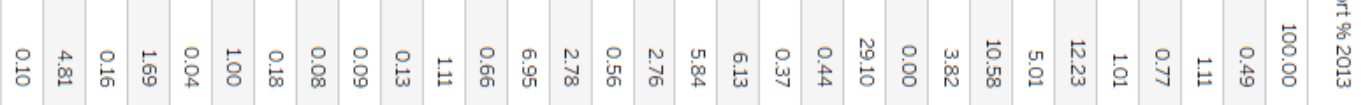

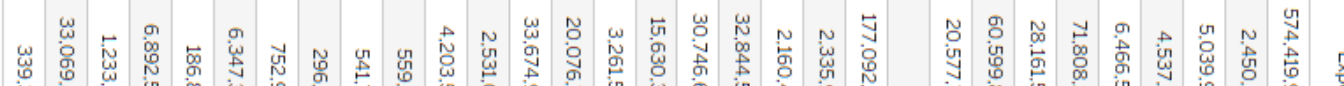

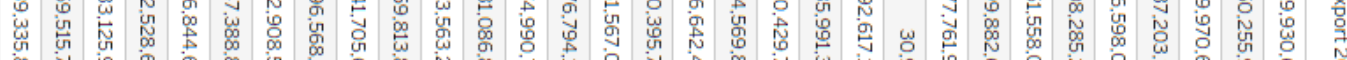

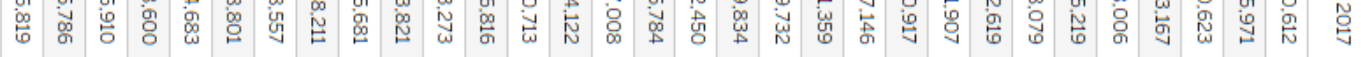

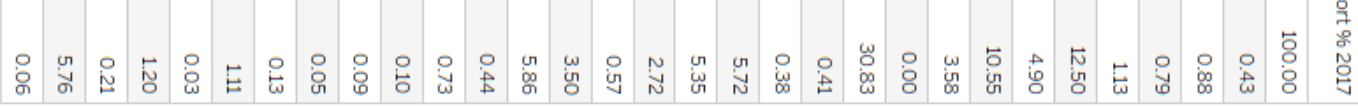

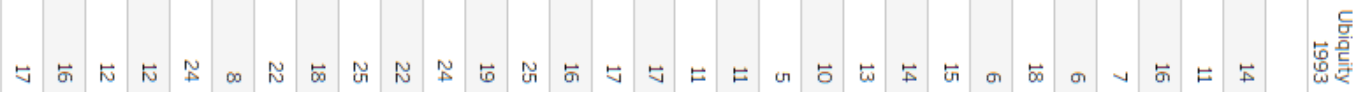

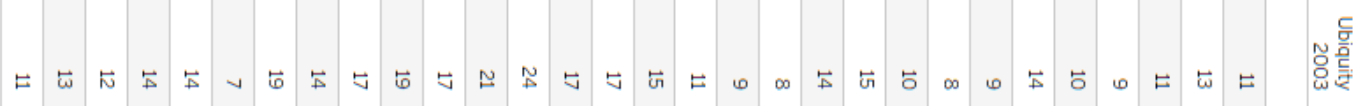

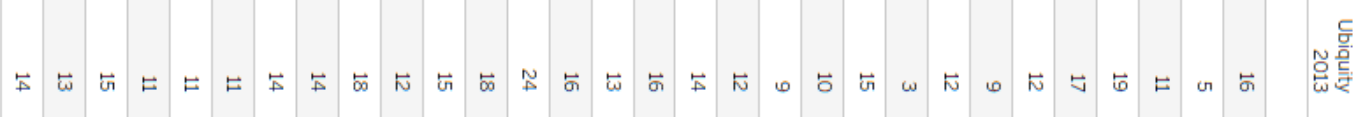

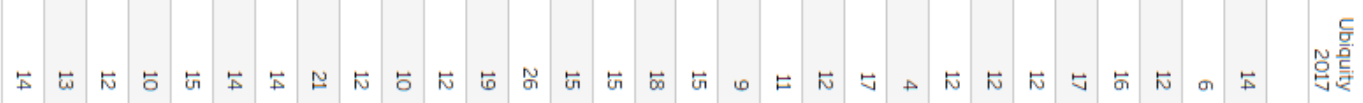

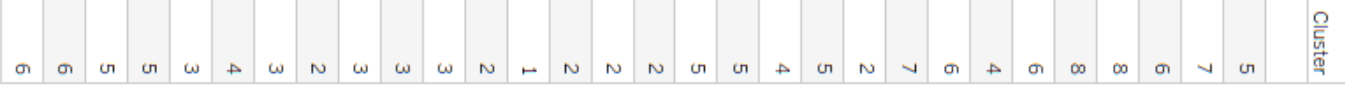




\section{Annex 4 - Infomap input file: weights and optimal relax-rate}

\section{Definition of the weight variables}

To produce the .net file, to be used as input for Infomap, it was necessary to define the weight to be assigned to the individual relationships between the nodes across layers. Specifically, for each year, we used the percentage weight of the value of each transaction on the total amount of the transaction value (i.e. for all components and parts) in the year ${ }^{31}$

Table A9 - Parameters of the distribution of the percentage weight of export transactions on the total export per year

\begin{tabular}{lllllllll}
\hline year & Count & Mean & st.Dev. & Min & 1st Qu. & Median & 3st Qu. & Max \\
\hline 1993 & 22749 & 0.00440 & 0.05192 & $4.17 \mathrm{E}-07$ & $8.22 \mathrm{E}-06$ & 0.00005 & 0.00043 & 3.26843 \\
2003 & 32645 & 0.00306 & 0.03569 & $3.84 \mathrm{E}-10$ & $2.34 \mathrm{E}-06$ & 0.00002 & 0.00026 & 2.36051 \\
2013 & 36550 & 0.00274 & 0.02421 & $1.88 \mathrm{E}-10$ & $1.87 \mathrm{E}-06$ & 0.00002 & 0.00034 & 1.63069 \\
2017 & 36620 & 0.00273 & 0.02497 & $1.74 \mathrm{E}-10$ & $1.50 \mathrm{E}-06$ & 0.00002 & 0.00032 & 2.22185 \\
\hline
\end{tabular}

Based on the information provided by mapequation.org (Edler, Eriksson, and Rosvall) at https://www.mapequation.org/infomap/\#InputMultilayerIntra, an extract from the structure of the .net file for export in 2017 is therefore:

*Vertices 42

1 "ARE"

2 "ARG"

3 "AUS"

...

41 "GBR"

42 "US"

*Intra

\# layer_id node_id node_id weight

$1130.000436 \overline{500580796818}$

$1148.43163640725565 \mathrm{e}-06$

1150.00019459248198603

$\cdots$

\section{Identification of optimal relax rate}

To determine the optimal relax-rate over the four years (for import and export), the procedures developed by Mangioni et al. (2018) have been implemented with Python.

The information loss values have been calculated for centesimal values of the relax rate, with number of trials equal to 1000,1500 and 3000 , using the following command to run Infomap: for rate in $1 \mathrm{E}-6$ \$(seq -w $0.010 .01 \$ \max )$; do

31 Gorgoni, Amighini, and Smith (2018) use a different weight: "For each of the auto components examined, a value is given to the trade relationship (i.e. tie) between any two pairs of countries [ij] according to the value of their bilateral trade flow [wij] over the world's total for that good in a specific year. " 
printf "Running for relax rate $\% .2 \mathrm{f}$.... $\mathrm{r}$ " "\$rate"

\# Generate the .map file for the alluvial plot generator each .2

increment

case $\$$ rate in

$1 \mathrm{E}-6|0.20| 0.40|0.60| 0.80 \mid 1.00)$

$$
\text { map="--map" }
$$

;

*)

$$
\text { map }=" "
$$

;

esac

infomap/Infomap --multiplex-relax-rate "\$rate" \

--include-self-links --num-trials 1000 --seed 1234 --two-level -d \

--input-format multiplex --out-name "relax\$rate" --expanded --clu "\$map" \

--silent "\$@" "\$network_data" "\$dest" done

printf "Running for relax rate \%.2f ... DONE $\backslash n$ " "\$rate"

Figure A3 - Export and Import - Normalized Information Loss
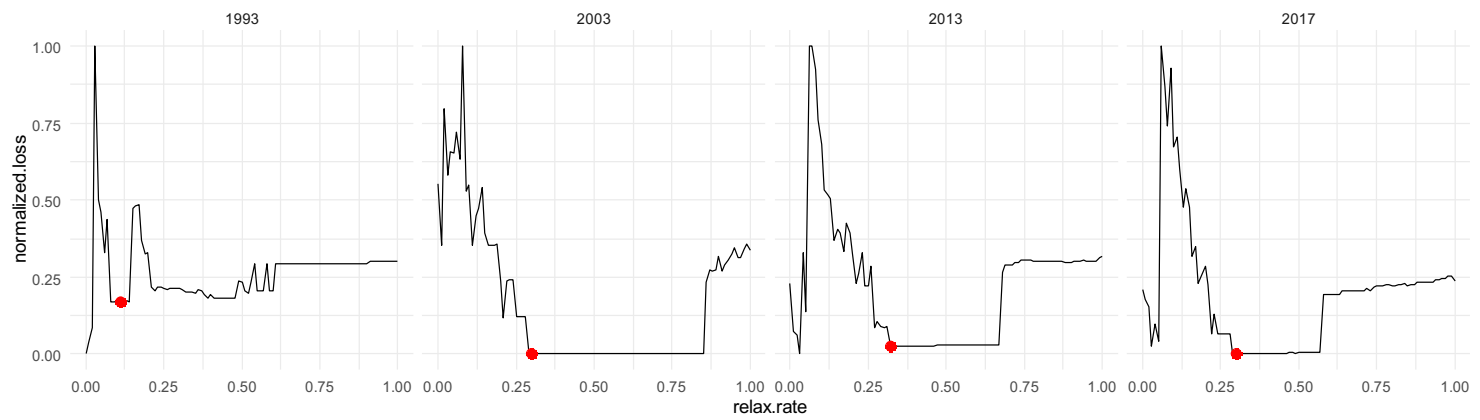

Table A10 - Optimal relax rate for import export share trade flows

$\begin{array}{llc}\text { year } & \begin{array}{l}\text { Optimal } \\ \text { relax.rate }\end{array} & \begin{array}{c}\text { Number of } \\ \text { modules }\end{array} \\ 1993 & 0.11 & 37 \\ 2003 & 0.30 & 16 \\ 2013 & 0.32 & 16 \\ 2017 & 0.30 & 17\end{array}$


Annex 5 - Infomap flow and Page Rank

Figure A11 - Infomap flow vs. Page Rank, by country, in 1993 and 2017

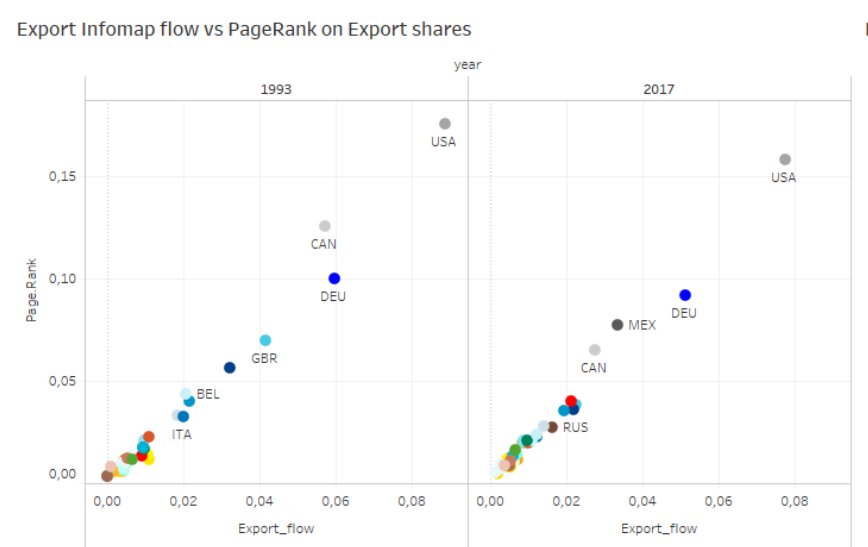

Import Infomap flow vs PageRank on Import shares

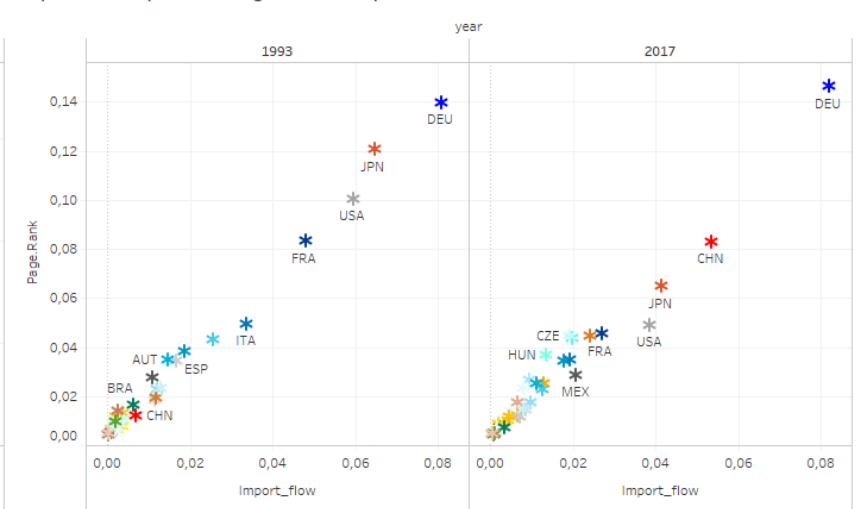

Source: Authors' elaboration on UN Comtrade International Trade Statistics Database 


\section{Annex 6 Infomap output files under analysis to study the flow between clusters}

For each state-node, we integrate the following Infomap output file .flow, containing enter flow and exit flow from each state-node

\# flow in network with 2446 memory nodes (from-to) and 4264276 links

(1 1) (flow: 0.000281759, enter: 0.000281759, exit: 0.000300978)

--> (1 3) (8.02382e-06)

$-->(14)(1.54992 \mathrm{e}-07)$

$-->(15)(3.57703 \mathrm{e}-06)$

--> (1 8$)(9.2298 \mathrm{e}-08)$

...

$<--(13)(3.16565 \mathrm{e}-08)$

$<--(15)(3.78119 \mathrm{e}-09)$

$<--\left(\begin{array}{ll}1 & 6\end{array}\right)(8.53595 \mathrm{e}-08)$

with:

- cluster of the origin state-node and cluster of destination state-node;

- shares of export and import for each state-node pair;

- the flow type: within if the flow is inside the same cluster (cluster.from=cluster.to), between if the flow is between different clusters.

cluster.from cluster.to country.from country. to SITC.from SITC.to trade_flow. from trade_flow. to flow.type flowIN flowOuT share_Exp share_Imp $2 \quad 2 \quad$ ARE $\quad$ AUS $6251 \quad 6251 \quad$ Export $\quad$ Export within 3.17E-08 8.02E-06 $4.37 \mathrm{E}-04 \quad 6.31 \mathrm{E}-07$

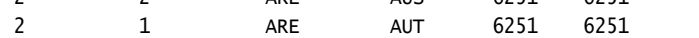

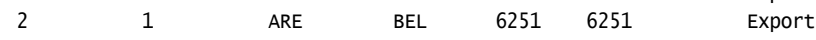

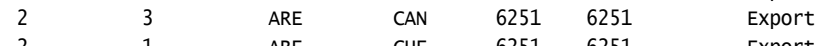

$2 \quad 1 \quad$ ARE $\quad$ DEU $6251 \quad 6251 \quad$ Export

Export between $1.55 \mathrm{E}-07 \quad 8.43 \mathrm{E}-06$

Export between $3.78 \mathrm{E}-09 \quad 3.58 \mathrm{E}-06 \quad 1.95 \mathrm{E}-04 \quad 7.49 \mathrm{E}-07$

Export between 2.58E-06 $9.23 \mathrm{E}-08 \quad 5.02 \mathrm{E}-06 \quad 3.36 \mathrm{E}-04$

Export between 7.51E-08 4.08E-06

Export between 1.74E-05 2.01E-06 $1.09 \mathrm{E}-04 \quad 4.83 \mathrm{E}-03$

Data is in csv files: flowIE1993.csv, flowIE2003.csv, flowIE2013.csv and flowIE2017.csv.

$\begin{array}{ll}\text { Year } & \text { n.records } \\ 1993 & 3601034 \\ 2003 & 4922170 \\ 2013 & 5195240 \\ 2017 & 5172892\end{array}$




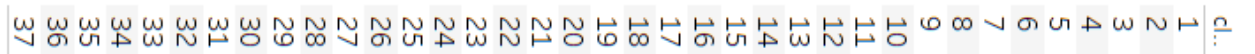

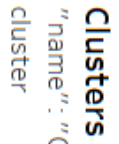

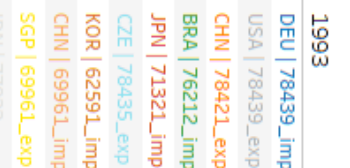

空空

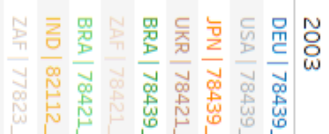

疍

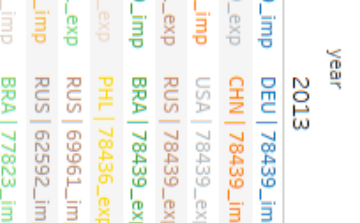

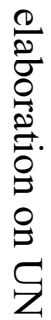

$\vec{N} \mapsto \vdash \bullet$ •

u

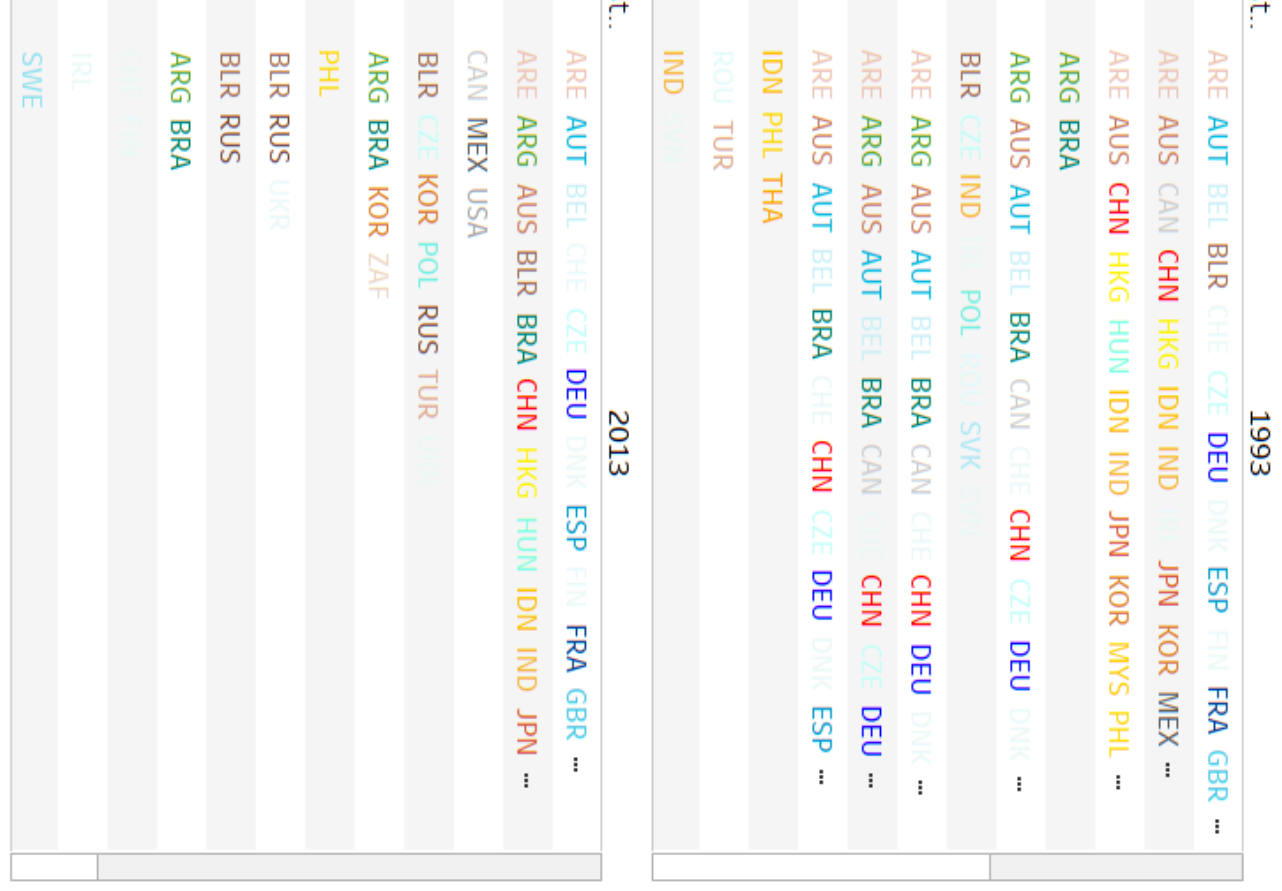

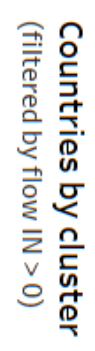

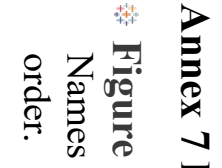

年

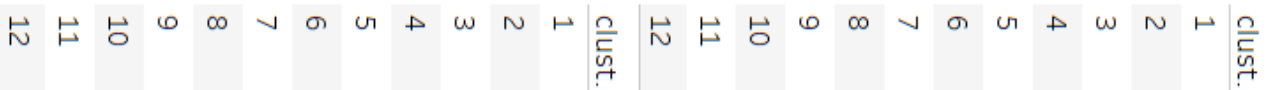

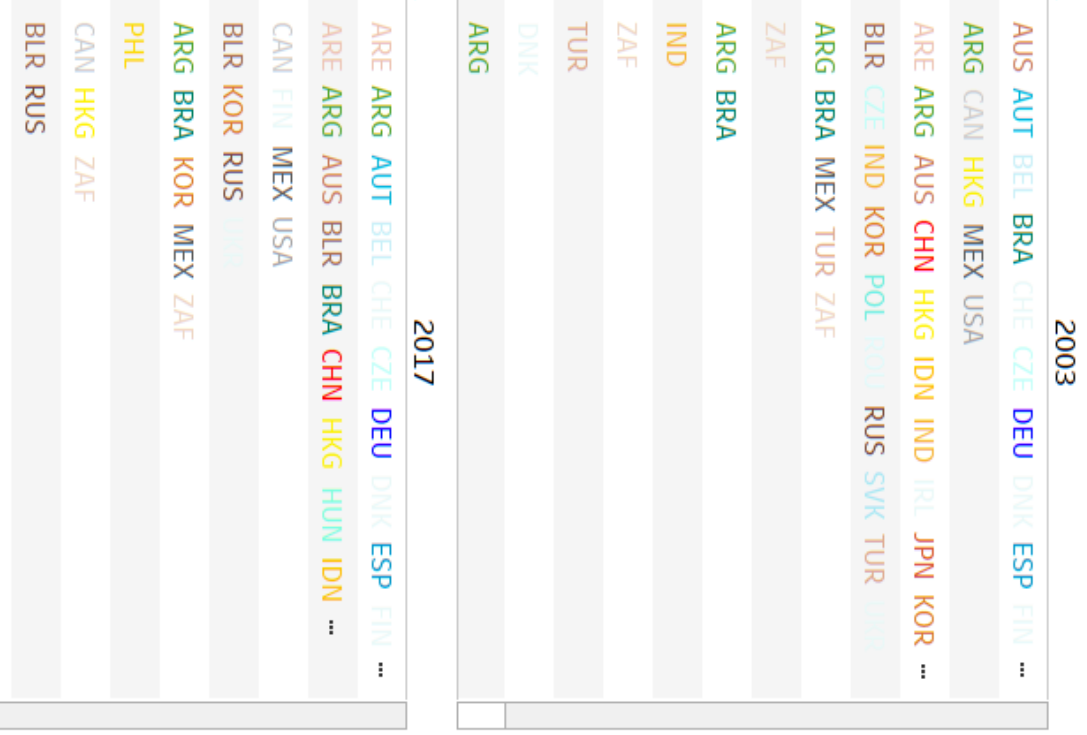




\section{Annex 8 - Items classified in the SITC codes 713.21, 713.22 and 713.23}

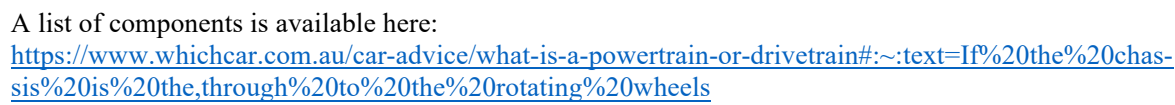

713.21

Engines, gasoline, internal combustion, for vehicles of division 78, group 722 and headings $744.14,744.15$ and 891.11 , of a cylinder capacity not exceeding 1,000 cc Engines, petrol, internal combustion, for vehicles of division 78, group 722 and headings $744.14,744.15$ and 891.11, of a cylinder capacity not exceeding 1,000 cc Engines, piston, internal combustion, for motor cycles, of a cylinder capacity not exceeding $1,000 \mathrm{cc}$

Engines, piston, spark-ignition, for vehicles of division 78, group 722 and headings $744.14,744.15$ and 891.11 , of a cylinder capacity not exceeding 1,000 cc

Engines, gasoline, internal combustion, for vehicles of division 78, group 722 and headings 744.14, 744.15 and 891.11, of a cylinder capacity exceeding 1,000 cc Engines, petrol, internal combustion, for vehicles of division 78, group 722 and headings 744.14, 744.15 and 891.11, of a cylinder capacity exceeding 1,000 cc Engines, piston, internal combustion, for motor cycles, of a cylinder capacity exceeding 1,000 cc

Engines, piston, spark-ignition, for vehicles of division 78, group 722 and headings $744.14,744.15$ and 891.11 , of a cylinder capacity exceeding 1,000 cc

Engines, diesel, for vehicles of division 78, group 722 and headings 744.14, 744.15 and 891.11

Engines, piston, compression-ignition, for vehicles of division 78, group 722 and headings $744.14,744.15$ and 891.11

Engines, semi-diesel, for vehicles of division 78, group 722 and headings 744.11, 744.15 and 891.11 